\author{
con $F-83101 \% 3-5 \%$ \\ COMPUTATIONAL METHODS FOR FRACTURE ANALYSIS OF \\ HEAVY-SECTION STEEL TECHNOLOGY (HSST) PRESSURE VESSEL EXPERTMENTS
}

B. R. Bass ${ }^{\dagger}$, R. H. Bryan, J. W. Bryson and J. G. Merkle

Oak Ridge National Laboratory*

Union Carbide Corporation. Nuclear Division

Oak Ridge, Tennessee 37830

$\cos 2-6310163--5 i$

DeUs 003327

\author{
BY acceptance of this article, the \\ publisher or recipient acknowledges \\ the U.S. Government's right to \\ retain a nonaxclusive, royelty-free \\ license in and to any copyright \\ covering the orticle.
}

\title{
DISCLAIMER
}

This report was prepared as an account of work sponsored by an agency of the United States Government. Neither the United States Government nor any agency thereof, nor any of their employees, makes any warranty, express of implied, or assume, any legal liabilicy or responsibility for the accuracy, completeness, or usefulness of any information, apparatus, product, or process disclosed, or represents that its use would not infringe privately owned rights. Reference herein to any specific commercial product, process, or service by trade name, trademark, manufacturer, or otherwise does not necessarily constitute or imply its endorsement, recommendation, or favoring by the United States Government or any agency thereof. The views and opinions of authors expressed herein do not necessarily state or reflect those of the United States Government or any agency thereof.

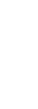

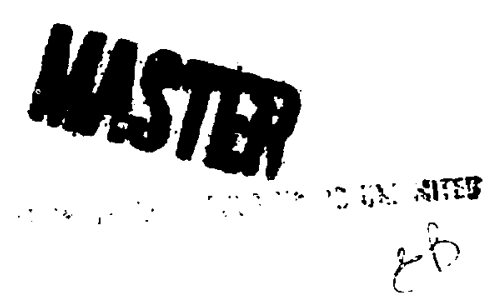

* Operated by Union Carbide Corporation under Contract W-7405-eng-26 with with the U. S. Department of Energy.

† Computer Sciences Organization, Union Carbide Corporation, Nuclear Division. 
COMPUTATIONAL METHODS FOR FRACTURE ANALYSIS OF HEAVY-SECTION STEEL TECHNOLOGY (HSST) PRESSURE VESSEL EXPERIMENTS *

\author{
B. R. Bass ${ }^{\dagger}$, R. H. Bryan, J. W. Bryson, and J. G. Merkle \\ Oak Ridge National Laboratory \\ Oak Ridge, TN 37830
}

SUMMARY

This paper summarizes the capabilities and applications of the general-purpose and special-purpose compuier programs that have been developed at the Oak Ridge National Laboratory (ORNL) for use in fracture mechanics analyses of HSST pressure vessel experiments. Emphasis is placed on the OCAVUSA code, which is designed for analysis of pressurized-thermalshock (PTS) conditions, and on the ORMGEN/ADINA/ORVIRT system which is used for more general analysis. Fundamental features of these programs are discussed, along with applications to pressure vesse? experiments.

\title{
1. INTRODUCTION
}

Several general-purpose and special-purpose computer prog:ams have been developed at ORNL for use in analyzing the fracture response of thickwalled pressure vessels tested in conjunction with the HSST program. The programs perform static analyses of brittle or ductile fracture in twodimensional (2-D) or fully three-dimensional (3-D) geometries. Table 1 summarizes the status and capabilities of each fracture code and indicates the relevant ORNL user documentation for each one. In this paper, the emphasis is placed on capabilities of the OCA/USA program, which is being used for assessments associated with PTS experiments at ORNL, and the ORMGEN/ADINA/ORVIRT system which is used for more general analysis. The ORMGEN/ADINA/ORVIRT system is presented first, followed by applications that include pretest planning and posttest analyses of the ITV V-8A test. that was concerned with ductile tearing in a low upper-shelf toughness weldment. This is followed by a discussion of the OCA/USA program and by sample results from applications to the ORNL PTS test configuration.

* Research sponsored by the Office of Nuclear Regulatory Research, U. S. Nuclear Regulatory Commission under Interagency Agreements 40-551-75 and 40-552-75 with the U. S. Department of Energy under Contract W-7405-eng-26 with the Union Carbide Corporation.

† Computer Sciences Organization, Inion Carbide Corporation, Nuclear Division.

By acceptance of this article, the publisher or recipient acknowledges the U. S. Government's right to retain a nonexclusive, royalty-free license in and to any copyright covering the article. 


\section{THE ORYGEN/ADINA/ORVIRT SYSTEM}

\section{1 Program Description}

The finite element analysis system, ORMGEN/ADINA/ORVIRT, is a threeprogram system that addresses linear and nonlinear stati: fracture in 2and 3-D crack geometries. Program ORMGEN (1)* automatically generates a complete 3-D finite element model of the cracked structure and creates data files which have formats compatible with the ADINA (2) structural analysis program. Special elements that introduce an appropriate stress singularity are used along the crack front. Program ORVIRT (3) acts as a postprocessor of the conventional ADINA analysis. ORVIRT employs a virtual crack extension technique for the calculation of energy release rates at specified points along the crack front.

ORMGEN presently has a library of six 3-D crack geometries which are illustrated in Fig. 1 and are currently of incerest to the HSST Program. The library of crack geometries includes flat plates with straight or curved surface cracks and cylinders with part-through cracks on the outer or inner surface. The curved cracks may be semicircular, semielliptical, or user defined. The straight crack in the plate configuration (Fig. 1(b)) is a through-crack, while for a cylinder it is a part-through crack (Fig. 1(d) and Fig. 1(f)). A cladding option is available that allows for either an embedded or a penetrating crack in the clad material. For each of these six crack geometries, ORMGEN provides ADINA-formatted data files that include nodal point coordinates, element connectivities, and appropriate displacements and pressure boundary conditions.

The strategy employed in ORMGEN is to surround the crack front with a core of special crack tip elements (see Fig. 2) and to model the remainder of the structure wi th conventional 20-node isoparametric brick elements. Element group I of the finite element model consists of the inner core of special crack tip elements enclosed by a single layer of conventional brick elements (Fig. 2). The remaining conventional brjok el ements of the model constitute element group II.

The special crack tip elements are employed along the crack front to model the appropriate singularity in the stress field. For linear elastic calculations, the quarter-point wedge element of Fig. 3 (a) is used at the crack front to allow for a $1 / \sqrt{r}$ singularity in the stress and strain fields (4), where $r$ is the radial distance from the crack tip. Figure $3(b)$ illustrates the collapsed prism element appropriate for a perfectly plastic material, with midside nodes that allow for a $1 / r$ singularity at the crack front (4). In the collapsed element, the nodes that initially share the same locations at the tip will separate with increasing load to allow for

\footnotetext{
* Numbers in parentheses refer to the references given
} at the end of this paper. 
blunting of the crack (see Fig. 4). The program allows the user to select either of the two special crack tip elements, depending upon whether the application is for linear elastic fracture analysis or for ductile fracture analysis.

The ORVIRT fracture mechanics program utilizes a virtual-crackextension technique developed by deLorenzi (5) for isothermal applications and modified by Bass and Bryson ( $\underline{6})$ to account for thermal strains in cracked bodies. The technique requires calculation of the released energy $G^{*}$ corresponding to a smail crack advance in a eracked body subjected to surface tractions $F_{\alpha}$, body force $f_{\alpha}$, and temperature distribution I (see Fig. 5). Points of configuration I (prior to crack advance) are mapped into configuration II (after crack advance) by the mapping

$$
\bar{x}_{\alpha}=x_{\alpha}+\Delta x_{\alpha}\left(x_{\beta}\right)
$$

where $x_{\alpha}, \vec{x}_{\alpha}$ correspond to coordinates in configurations $I$ and II, respectively, and $\Delta x_{\alpha}$ is the incremental change in coordinates. From Refs. 5 and 6 , the total energy release rate $G_{T}$ is given by

$$
G_{T}=G^{*} / \Delta A
$$

where $\triangle A$ is the area increment covered by the virtual extension of the crack front (see Fig. 6), and

$$
\begin{aligned}
\mathrm{G}^{*}= & \int_{V}\left(\sigma_{\alpha \beta} \frac{\partial \mathrm{u}_{\alpha}}{\partial \mathrm{x}_{\delta}}-\mathrm{w}_{\delta \beta}\right) \frac{\partial \Delta_{\delta}}{\partial \mathrm{x}_{\beta}} \mathrm{dV} \\
& +\int_{V}\left(\sigma_{\alpha \beta} \frac{\partial \theta_{\alpha \beta}}{\partial \mathrm{x}_{\delta}}-\mathrm{f}_{\alpha} \frac{\partial \mathrm{u}_{\alpha}}{\partial \mathrm{x}_{\delta}}\right) \Delta \mathrm{x}_{\delta} \mathrm{dV}
\end{aligned}
$$

In Eq. (3), $\sigma_{\alpha \beta}$ are the components of the stress tensor, $u_{\alpha}$ are displacement components, $\theta_{\alpha \beta}$ are the strains of free thermal expansion, $x_{\delta}$ are spatial coordinates, and $d V$ is the volume differential. The strain energy density $W$ is given by

$$
w=\int_{0}^{\varepsilon^{\prime} \gamma \delta} \sigma_{\alpha \beta} \mathrm{d} \varepsilon_{\alpha \beta}^{\prime}, \varepsilon_{\alpha \beta}^{\prime}=\varepsilon_{\alpha \beta}-\theta_{\alpha \beta},
$$

where the mechanical strain components $\varepsilon_{\alpha \beta}^{\prime}$ are defined in terms of the total strains $\varepsilon_{\alpha \beta}$ and the thermal strains $\theta_{\alpha \beta}$. Average and local values of $G_{T}$ are evaluated, respectively, from uniform and local virtual extensions of the crack front (see Fig. 6). 
In app. ications, the energy release rate $G_{7}$ of Eqs. (2), (3) is evaluated numerically from solution data written to the nodal point and element portholes of ADINA and from a user-supplied virtual extension $\Delta \mathrm{x}_{\alpha}$ of the crack front. The ORMGEN mesh generator program interfaces with the ${ }^{\alpha}$ ORVIRT program to perform this integration in a particularly efficient manner. When applied to an ORMGEN-generated finite element model, program ORVIR- evaluates the volume integral of $\mathrm{Eq}$. (3) only over the crack front element group I (Fig. 2), using a virtual crack extension file created automatically by ORMGEN.

\subsection{Applications to the V-8A Pressure Vessel Test}

The ORMGEN/ADINA/ORVIRT system has been applied to pretest planning and to posttest analyses of the ITV V-3A test (7) conducted by the HSST program. The objective of the test was to provide accurate quantitative data concerning the growth of ductile tearing and final instability of a crack in a low upper-shelf toughness weldment located in a cylinder of reactor vessel steel. The motivation for performing this test is the there are vessels in service containing welds which, because of high copper content, may have their Charpy upper-shelf energy values reduced to relatively low levels by neutron irradiation. After some period of operation, the toughness of these welds is expected to be degraded to the extent that practical operating temperature limits may not be attainable in accordance with present regulatory guidelines. The results of the $\mathrm{V}-\mathrm{BA}$ test are intended to provide an experimental basis for judging the accuracy of vessel fracture safety analysis procedures for low upper-shelf toughness conditions.

The purposes for which the V-8A test plan was formulated are (1) to demonstrate the fracture behavior of low-toughness material at upper-shelf temperatures and (2) to provide a basis for comparisons between elasticplastic fracture-mechanics predictions of stable and unstable tearing and full-scale test results. Accordingly, the plan involved the placement of a large crack in a special low upper-shelf weld seam that was in turn placed in a test vessel as shown in Fig. 7. A crack having an approximate semielliptical profile $280 \mathrm{~mm}$ long by $70 \mathrm{~mm}$ deep was machined in the seam and fatigue-cycled to a depth of $88 \mathrm{~mm}$. Pretest ultrasonic measurement indicated that the initial crack was $91 \mathrm{~mm}$ deep. Then, with the vessel heated to the proper temperature, the vessel was pressurized slowly with intermittent pauses for recording data related to crack growth until unstable tearing was oftected. After an instability was observed, the vessel was depressurized to preserve the crack and the vessel for further examination.

For the final pretest predictions of crack behavior, three-dimensional finite element analyses were performed with ORMGEN/ADINA/ORVIRT for a range of crack depths and internal pressures using a material model that is based on the deformation theory of plasticity (2). Energy release rates computed from these analyses were compared with available tearing resistance data to estimate the onset of stable tearing as well as unstable tearing of the crack. Figures 8 and 9 show the dimensions of a quarter section of the 
test vessel as modeled and a portion of the finite element discretization generated by ORMGEN. The experimental material response (uniaxial stressstrain curve) was modeled using a multilinear approximation as depicted in Fig. 10. For the models that were analyzed, values of material properties were taken to be:Young's modulus $E=0.2095 \times 10^{6}$ $\mathrm{MPa}$, Poisson's ratio $v=0.3$, and initial yield stress $\sigma_{y}=427.5 \mathrm{MPa}$.

Results from the analysis of one of these cases, V8EP9 (a=98 mm, $b=140 \mathrm{~mm})$, are presented in Fig. 11 in terms of $J_{I}(\phi, p)$, where $J_{I}=G_{T}$ is evaluated from Eq. (2): pressure $p$ is a parameter. I The $J$ yalues peak sharply around $\phi=20^{\circ}$ to $30^{\circ}$ at the higher pressures $(140-155 \mathrm{MPa})$, in contrast to the $\mathrm{J}$ distribution for pressures producing no large-scale yielding ( $105 \mathrm{MPa}$ ). The computed $J$ values were used in conjunction with measured tearing resistance curves (g) (Fig. 12) to make estimates of $\mathrm{J}_{\mathrm{R}^{-}}$ controlled tearing. The scheme for determining the progression of $\mathrm{J}_{-}^{-}$ controlled tearing is illustrated in Fig. 13. If a crack has an initial depth $a_{0}$. then at some pressure, $\mathrm{p}_{\mathrm{g}}$, the condition $\mathrm{J}_{\mathrm{J}}=\mathrm{J}_{\mathrm{R}}$ is satisfied when $a={ }^{\circ}$, and $J_{I}=J_{R 1^{\circ}}$. In this particular instance, as shown in Fig. 13. at a constant pressure, $p_{1}$. a virtual increment in crack depth beyond a would cause $J_{R}$ to increase more than $J$ with the result that $J J_{B} J_{J}$. This implies that more energy would be required to generate the virtual extension than could be supplied by the strain energy released; thus, $a$ is a stable crack depth. At crack depths $a_{2}$ and $a_{3}$, a virtual extension would result in $J_{I}>J_{R}$ and a tearing instabilfty. Pressure $p_{2}$ is the maximum pressure determined by this procedure for which $J_{I}=Z_{R}$ and is therefore defined as the tearing instability pressure.

Two independent ORNL predictions of conditions for tearing instability were made on the basis of the $J_{R}$ curves of Fig. 12 and results from applications of ORMGEN/ADINA/ORVIRT to a series of crack models ( 7 ). These predictions, along with those made by other groups, are shown in Table 2. The diverseness of the resistance curves accounts for the differences in ORNL predictions of the instability pressure. The ORNL predictions for stable crack growth were not very sensitive to the choice of a $J_{R}$ curve. A.1 of the estimated instability pressures are within the range of 37 to $110 \%$ of the measured instability pressure of $\sim 139 \mathrm{MPa}$. The predicted estimates of crack growth prior to instability range from 6.8 to $15 \mathrm{~mm}$.

Pfter the $V-8 A$ test, the segment of the weld containing the crack was cut from the vessel and split to expose the crack surface. Figure 14 shows clearly the initial machined and fatigue-sharpened profiles as well as the final canoe-shaped profile attained in the test. Measurements of initial and final crack dimensions indicate that the pretest values given in Table 3 were reasonably accurate. Results of the $J_{R}$ specimen test $(10)$ for the weld material are given in Fig. 12 and show that the $\mathrm{V}-8 \mathrm{~A}$ weld seam had a relatively low tearing resistance when compared to characterization weld data. 
Additional fracture analyses of the $v-8 A$ test are being performed on the basis of these posttest measurements of geometry and properties. Figure 15 illustiates a series of four crack profiles, where profile 1 is the initial configuration and profile 4 the final configuration, that were analyzed with the ORMGEN/ADINA/ORVIRT system. The ORMGEN-genercted finite element model of profile 4 is depicted in Fig. 16. Results from these four analyses are presented in Figs. $17-21$ for $J_{I}(\phi, p)$ and in Fig. 22 for crack mouth opening displacement (CMOD). These analyses indicate that the peak values of $J_{I}$ associated with the initial profile 1 for $\phi \approx 20^{\circ}$ and $\mathrm{p}_{0} \geq 135$ $\mathrm{MPa}$ are reduced relative to the maximum depth values at $\phi=90^{\circ} \mathrm{a}$ s the crack profile progressively takes on the canoe-like shape of the final configuration. This is illustrated by the family of $J_{I}(\phi, p)$ curves shown in Fig. 21 for the progression of four crack profiles at a single pressure, $135 \mathrm{MPa}$ (near which most of the tearing occurred in the test). Profile 1 (semi-ellipse) shows a relatively high driving force for crack extension in the directions of $10^{\circ} \leq \phi \leq 20^{\circ}$; progressive canoeing (profiles 2-4) appears to diminish this tendency. These analvtical results are in agreement qualitatively with the experimental observations that little, if any, axial crack growth occurred at pressures below - $138 \mathrm{MPa}$, while extensive canoeing occurred at or above this preisure.

Further analyses are currently under way that combine the above

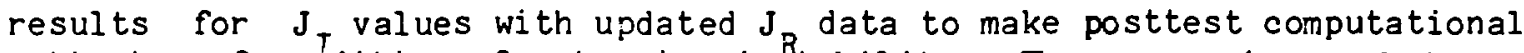
estimates of conditions for tearing instability. The comparisons between measured and computed CMOD values in Fig. 22 reflect that the stress-strain curve of $\mathrm{Fig}$. 5 used to model the vessel material is overly stiff in the elastic region. An adjusted stress-strain curve that reflects the posttest measured properties will be employed in a repetition of the above analyses.

\section{THE OCA/USA PROGRAM}

\section{1 Program Description}

Extensive computational analyses are being performed to determine material parameters and optimum pressure-temperature transients compatible with proposed pressurized-thermal-shock (PTS) test (11) scenarios and with the capabilities of the PTS test facility (Fig. 23) at ORNL. Both linear and nonlinear material models are employed, as well as 2-D and $3-D$ finite element representations of crack geometries. Computational economy requires application of techniques suitable for parametric studies involving a large number of transients. These techniques, which include the use of a 3-D superposition method, an inelastic ligament stability assessment, and an upper-shelf arrest araiysis, have been incorporated into the previously developed OCA-I (12) code to form the OCA.USA computer program. 
Basic calculations performed by OCA/USA are (1) a thermal analysis to provide the temperature history through the vessel wall; (2) a stress analysis that provides the circumferential stresses for the uncracked cylinder for combined pressure-thermal loading; (3) computations of initiation factors $K_{\text {s }}$ and arrest factors $K_{\text {as }}$ anctions of crack depth and time from material property data and temperature history: (4) 2-D and 3-D superposition analyses that provide the stress intensity factors $K_{\text {as }}$ a function crack depth and time: (5) an interpolation of the computed factors $\mathrm{K}_{\mathrm{I}}$, the initiation factors $\mathrm{K}_{\mathrm{I}}$, and the arrest factors $\mathrm{K}_{\mathrm{Ia}}$ to determine the times for each crack depth at which $K_{I}=K_{I c}, K_{I}=K_{I a}$, and $d K / d t=0 ;(6)$ a ligament stability analysis based on an ideally-plastic material model; ( 7 ) an uppar-shelf arrest analysis based on tearing resistance $\left(\mathrm{J}_{\mathrm{p}}\right.$ ) criteria; $(8)$ extensive postprocessing graphics output. Items (1), (2), (3), (4) (for 2-D superposition), (5), and (8) above have been described in Ref. (12) and the remaining items (4) (for 3-D) superposition), (6), and (7) e presented here.

The surface crack shown in Fig. 23 was analyzed initially by assurning an infinitely long (2-D) crack and using superposition techniques to calculate $K_{I}$ factors for time-dependent combined pressure and thermal

loading. Io cbtain improved estimates for $K$ values, direct 3-D calculations (13) were performen with ORMGEN/ADINA/ORVIRT for a range of depth ratios; the crack was postulated to grow deeper without increasing in length. To avoid the prohibitively high computing cost of the direct 3-D approach for time-varying houndary conditions, an alternative superposition technique $(4,15)$ was adopted. Considerable economy $c$ an be achieved in this apprcach since the only 3-D solutions required are those used to calculate a set of influence coefficients for a given crack model. In Fig. 24, these influence coefficients are stress intensity factors $j_{K}(\phi), j=0,1,2,3$, computed from crack surface loading functions $\left.j_{O f} y\right)=(y / a)^{j}$. To obtain the $K_{I}(\phi)$ distrioution for an arbitrary loading condicion, the hoop stress distrioution $\sigma(y)$ from an uncracked cylinder is expressed as a third-order polynomial

$$
\sigma(y)=\sum_{j=0}^{3} c_{j}(y / a)^{j}
$$

Then, by superposition, the $K$ function is calculated from the influence coefficients ${ }^{{ }^{K}}{ }_{I}$ and the coefficients of Eq. (5) according to

$$
K_{I}(\phi)=\sum_{j=0}^{3} c_{j}{ }^{j} K_{I}(\phi)
$$


For the crack geometry of Fig. 23, the influence coefficients ${ }^{j} K_{I}(\phi)$ were calculated for a set of depth ratios $a / w=\{.1, .2, .3, .4, .5, .6, .9\}$ using the ORMGEN/ADINA/ORVIRT system. The 3-D superposition technique is compared in Fig. 25 with direct 3-D thermoelastic analyses from ORMGEN/ADINA/ORVIRT with the parameters of the PTS transient T1 given in Table 4. Results are presented for surface cracks of depth $a / w=0.1$ and 0.6. Also shown in the figure are results for infinitely long cracks of the same a/w ratios. The latter results illustrate the difference between infinite crack and finite crack models for the deeper cracks in this series.

Another consideration in the PTS transient is that the upper shelf be reached at a crack depth/pressure combination that precludes tensile instability of the remaining ligament. At the unstable crack depth corresponding to the ligament fully yielded in tension, stretching of the ligament causes large increases in crack tip opening displacement. The model implemented in OCA/USA for this condition assumes a deep continucus surface crack with complete ligament yielding, but wi thout strain-hardening (16). Because the crack is deep, a strip-yield type model was adopted such that yielding occurs only on the plane ahead of the tip. Thus, when the ligament is completely yielded, the stress distribution directly ahead of the crack is ideally plastic (Fig. 26).

In Ref. 16, a section of the cylinder (subjected to radially symmetric loading) is modeled as a cut ring ( $F i g .26$ ) with one face clamped and the other free. The crack face tractions are derived for the model and used to determine the crack face rotation $\theta$ and the ratio $d / b$. The latter ratio locates the hinge point or the point of stress reversal in the fully yielded remaining ligament. For the hinge point located inside the remaining ligament, $d / b>0$, the crack tip opening displacement $\delta$ is given by

$$
\delta=\theta w\left(\frac{b}{w}\right)\left(1-\frac{d}{b}\right)
$$

For the ligament fully yielded in tension and the hinge point located cutside the ligament, the stress distribution in the ligament is independent of the hinge point location, being the same as for $d=0$. The tip displacement for this case is given by

$$
\delta=-\Delta y-\theta w\left(\frac{1}{2}-\frac{b}{w}\right) .
$$


The foregoing model, implemented in the OCA/USA code, is compared with two other analyses in Fia. 27 for the PTS transient T1 of Table 4. The figure shows results from t... ideally-plastic ligament model at 6 min in the transient $T I$ in the form of a pseudo $K$-value obtained from the relations $K_{J}=\sqrt{E J}, J=\sigma_{y} \delta$, and $E q .(7)$ or ( 8 \%. At $a / w=0.69$, the ligament becomes completely yielded in tension, causing large increases in crack tip opening displacement. Ligament yielding causes $K$ to significantly exceed the linear elastic $k$ value pricr to development of complete tensile yielding in the remaining ligament. The lower intersection of the two curves identifies the crack depth below which the ideally-plastic analysis should be disregarded because the remaining ligament is not yet completely yielded. To evaluate the reliability of the yielded ligament model, direct thermo-elastic-plastic analyses were performed for a series of crack depths. These studies utilized 2-D plane strain finite element models, a deformation plasticity material model with initial thermal strains (9), a multilinear strain hardening curve having parameters described in Ref. 17 and the ORMGEN/ADINA/ORVIRT system. As expected, the latter analyses considering strain-hardening produced pseudo $\mathrm{K}$-values lying between the linear curve and the ideally-plastic curves of Flg. 27. These results emphasize the need to consider plastic instability in PTS analyses for deeper cracks.

An additional enhancement of OCA/USA was motivated by a proposed PTS test scenario in which the crack initiates in cleavage and propagates into a region where temperatures are sufficiently high for completely ductile fracture. An upper-shelf fracture model was developed which assumes the existence of a temperature $T$, above which ductile fracture (even theugh fast) prevails, and below which fracture is entirely by the cleavane mode. Transitional behavior involving simultaneous cleavage and ductile fracture during a small increment of cracks growth is ignored.

In PTS transients of practical interest, a growing crack runs into a monotonically increasing temperature field, with the ductile upper-shelf regime having $T>T_{D}$. Dynamic tests of large specimens indicate that $T_{D}$ is in the neighborhood of $\sim 100 \mathrm{~K}$ higher than the reference nil-ductility temperature RT $\mathrm{RT}_{\text {i }}$ at such temperatures crack arrest toughness data are generally unavailable. Under these circumstances, the extrapolated $\mathrm{K}_{\mathrm{I}}$ curve from Section XI (Appendix A) of the ASME code does not appear to 5 e the most reliable basis for planning upper-shelf arrest experiments. As an alternative, the model presented here utilized available tearing resistance $\left(J_{R}\right)$ data to determine whether a crack in the region $T>I_{D}$ is stable in a quási-static sense.

The procedure for cetermining upper-shelf stability is illustrated in Fig. 28. Temperatures in the wall of the vessel during a transient can be represented as contours in a crack depth vs time (a vs t) plot. Fig. 28(a). At a given time $t^{\prime}$, there is a crack depth $a^{\prime}$ at which temperature $T=I^{\circ}$. It is pestulated that the continued growth of the crack with depth a' is controlled by $\mathrm{J}_{\mathrm{R}}$, which is generally a functicn of incremental crack growth $\Delta a=a-a^{\prime}$ and crack tip temperature. As illustrated in Fig. 28(b) 
for $t=t^{\prime}$, the condition for crack growth is

$$
J_{I}(a)>J_{R}\left[a-a^{\prime}, T(a)\right]
$$

and for stability,

$$
J_{I}(a) \leq J_{R}\left[a-a^{\prime}, T(a)\right] \quad
$$

Application of the technique involves a plastic zone size correction to previously calculated $\mathrm{K}$ values, conversion of $\mathrm{K}$ to $\mathrm{J}$, and computation of stable and unstable upper-shelf points based on the criteria given by Eqs. (9)-(10). The point of incipient instability is defined as the last stable $\mathrm{J}_{\mathrm{R}}$-controlled crack depth.

\subsection{Application to Critical-Crack-Depth Analysis}

The objectives of the first PTS test to be performed at ORNL (PTSE-1) are to obtain (in chronologice? order):

1. first initiation in cleavage of a shallow crack prior to

first warm prestress (15) WPS 1 ,

2. first arrest in the transition region,

3. $\mathrm{K}_{\mathrm{T}} / \mathrm{K} \geq 1$ before the end of WPS 1 ,

4. frangible second initiation after WPS1 is relieved, and

5. ductile upper-shelf arrest of a fast-moving crack.

This section describes results from a critical-crack-depth analysis performed with the OCA USA program using parameters of PTS trial transient T2 in Table 4. The tearing resistance data are characterized by a power law curve, also given in Table 4. The computed factors $\mathrm{K}_{\mathrm{I}}$, the initiation factors $K$ and the arrest factors $K$ are interpolated by the program for a series ${ }^{I C}$ of crack depths $(0 \leq a / w \leq 0.9)$ to determine the times in the transient at which $K_{I}=K_{I}, K_{I}=K_{I a}$, and $d K_{I} / d t=0$. This information is output in the form of critical-crack-depth curves that indicate behavior of the crack during portions of the transieni. The curves for transient T2 are presented following a discussion of the criteria used to establish optimum test parameters.

Test parameters are selected to satisfy the criteria summarized in Fig. 29 for a representative $K$ vs time transient. These criteria are necessary to account for experimental uncertainties and to provide conclusive evidence of the fracture mechanisms being studied. The first. two criteria ensure that the ratio $K_{I} / K_{I c}$ is sufficient to guarantee initiation prior to WPS1. The third criterion ensures that $K_{I}$ is greater than $K_{T}$ when WPS 1 is removed; in this event there would be no ambiguity about the cause of reinitiation. The fourth criterion ensures that, before the onset of WPS2, the post-WPS1 value of $K_{I}$ will exceed the maximum value initially cbtained: this allows for the possibility that initiation after 
WPS: requires a higher $K_{I}$ value. The fifth criterion establishes a negative $\mathrm{dK} / \mathrm{dt}$ during WPS1. The sixth criterion ensures a frangible second initiation. The seventh and eighth criteria imply that cleavage arrest would not intervene in the interval $t_{5}<t<t_{6}$ and that arrest would occur on the ductile upper shelf without ligament instability.

Figure 30 shows the critical-crack-depth and $K_{T}$ vs time plots generated by OCA USA for transient T2 of Table 4. The curves are constructed by the program from the larger $K_{T}$ value calculated at each crack depth in two 2-D analyses: the ideally-plastic ligament analysis and the superposition analysis with plastic zone size correction. For $(\mathrm{a} / \mathrm{w})=$ 0.05 , the first initiation and arrest event can occur in the time interval $0.95 \mathrm{~min} \leq t \leq 2.0 \mathrm{~min}$, with arrest in the interval $0.11 \leq(\mathrm{a} / \mathrm{w}) \leq 0.20$. The first WPS starts 2 min into the transient and lasts until the pressure ramp is initiated 4 min later. The crack again becomes critical $\left(K_{\mathrm{I}} / \mathrm{K}_{\mathrm{Ic}} \geq\right.$ i) before the end of WPS1, with the second initiation taking place Ibetween $^{-}$ 6 and $8 \mathrm{~min}$. Initiation is frangible and, if prior to $7.3 \mathrm{~min}$, the arrest will be on the upper shelf in the interval $0.50 \leq(\mathrm{a} / \mathrm{w})$ usA $\leq 0.77$ : a crack initiating after $7.3 \mathrm{~min}$ will not arrest. The ideally-plastic ligament instability curve, also given in Fig. 30, indicates that a plastic instability would not interfere with stable tearing of the crack for the second initiation occurring earlier than $7.3 \mathrm{~min}$. The results presented in Fig. 30 demonstrate that, by restricting $t_{6}<7.3 \mathrm{~min}$, transient $\mathrm{T} 2$ satisfies all but criteria 4 and 7 listed in Fig. 29 when analyzed by a 2-D model. Further evaluation of the transient requires that the criticalcrack-deptin analysis be repeated using max $K_{I}(3-D$ values obtained from the 3-D superposition technique and subjected to $I$ plastic zone size correction (not shown due to space limitations). Final selection of PTS test paraneters will be influenced by additional analyses that examine the sensitivity of the criteria to variation in material properties and test conditions and by fully 3-D thermo-elastic-plastic analyses.

\section{ACKNOWLEDGMENT}

This work was supported by the U. S. Nuclear Regulatory Commission through the Heavy-Section Steel Technology program at the Oak Ridge National Laboratory. Oak Ridge, Ternessee. The Oak Ridge Nationa: Laboratory is operated by Union Carbide Corporation, Nuclear Division, for the U. S. Department of Energy under U. S. government contract $W-7405$ eng 26 . 


\section{REFERENCES}

1. BASS, B. R, and BRYSON, J. W. Applications of Energy Release Rate Technique to Part-Through Cracks in Plates and Cylinders, Volume 1. ORMGEN-3D: A Finite Element Mesh Generator for 3-Dimensional Crack Geometries. NUREG/CR-2997, Vol. 1 (ORNL/TM-8527/V1), Oak Ridge National Laboratory, Oak Ridge, Tenn., December 1982.

2. BATHE, K. J。 "ADINA - A Finite Element Program for Automatic Dynamic Incremental Nonlinear Analysis" Report 82448-1, Massachusetts Institute of Technology, Cambridge, Mass., September 1975 (revised December 1978).

3. BASS, B. R. and BRYSON, J. W. Applications of Energy Release Rate Techniques to Part-Through Cracks in Plates and Cylinders, Volume 2. ORVIRT: A Finite Element Program for Energy Release Rate Calculations for 2-D and 3-D Crack Models, NUREG/CR-2997, Vol. 2 (ORNL/TM-8527/V2), Oak Ridge National Laboratory, Oak Ridge, Tenn., February 1983.

4. BARSOUM, R. S.

"Triangular Quarter-Point Elements as Elastic and Perfectly-.Plastic Crack Tip Elements" International Journal for Numerical Methods in Engineering, Vol. 11, 1977, pp. 85-98.

5. DELORENZI, H. G.

"On the Energy Release Rate and the J-Integral for 3-D Crack Configurations" TIS Report 80CRD113, General Electric Company, Schenectady, N. Y., June 1980.

6. BASS, B. R. and BRYSON, J. W. "Energy Release Rate Techniques for Combined Thermo-Mechanical Loading" Int. Journ. of Fracture, Yol. 22, p. R3, 1983.

7. BRYAN, R. H. , et al.

"Experimental Investigation of Tearing Behavior of a Flaw in a Thick Pressure Vessel" SMiRT Post Conference Seminar No. 6 , Monterey, Calif., August 29-30, 1983. 
8. BASS, B. R., et al.

"Deformation Theory of Plasticity with Initial Thermal Strains"

In: Heavy-Section Steel Technology Program Quarterly

Progress Report for January-March 1983.

NUREG/CR-3334, Vol. 1 (ORNL/TM-8787/VI), Oak Ridge National

Laboratory, Oak Ridge, Tenn., p. 3, September 1983.

9. DOMAIN, H. A.

"Vessel V-8 Repair and Preparation of Low Upper-Shelf Weldment"

Final Report, Contracts CRD-1055, CRD-1078, The Babcock and

Wilcox Company, Alliance, Ohio, January 1982.

10. DOMAIN, H. A. and FUTATO, R. J.

"J-Integral Test Results of HSST-ITV8A Low Upper Shelf Weld"

The Babcock and Wilcox Company, Alliance, Thio, submitted to Union

Carbide Corporation, Nuclear Division, 1983.

11. BRYAN, R. H. and McCULLOCH, R. W.

"Pressurized-Thermal-Shock Studies," In: Heavy-Section Steel

Technology Program Quarterly Progress Report for October-December 1982 , NUREG/CR-2751, Vol. 4, (ORNL/TM-8369/V4), Oak Ridge National Laboratory, Oak Ridge, Tenn., p. 79. May 1983.

12. ISKANDER, S. K. , CHEVERTON, R. D., and BALL, D. G.

OCA-I, A Code for Calcuiating the Behavior of Flaws on the

Inner Surface of a Pressure Vessel

ORNL/NUREG-84, Oak Ridge National Laboratory, Oak Ridge, Tenn.,

August 1981.

13. BRYSON, J. W. and McCULLOCH, R. W.

"Comparisons of 3-D and 2-D Computed K-Values for Outside Surface

Flawe in an ITV for Combined Pressure-Thermal Loading" In: Heavy-Section

Steel Technology Program Quarterly Progress Report for October-December

1982) NUREG/CR-2751, Vol. 4 (ORNL/TM-8369/V4), Oak Ridge National

Laboratory, Oak Ridge, Tenn., p. 87, May 1983.

14. IIELIOT, J., LABBENS, R. C., and PELLISSIER-TANON, A.

"Semi-Elliptical Cracks in a Cylinder Subjected to Stress Gradients."

In: Fracture Mechanics, ASTM STP677 (Ed. C. W. Smith), p. 341, 1979.

15. RAJU, I. S. and NEWMAN, J. C.

"Stress Intensity Factor Influence Coefficients for Internal and

External Surface Cracks in Cylindrical Vessels," In:

Aspects of Fracture Mechanics in Pressure Vessels and Piping,

ASME Pub. PVP Vol. 58, p. 37, 1982.

16. MERKLE, J. G.

"Elastic-Ideally-Plastic PTS Analysis for a Deep Continuous

External Longitudinal Crack in a Cylinder." In:

Heavy-Section Steel Technology Program Quarterly Progress Report

for January-March 1983, NUREG/CR-3334, Vol. 1 (ORNL/TM-8787/VI),

Oak Ridge National Laboratory, Oak Ridge, Tenn., p. 103.

September 1983. 
17. BASS, B. R., et al

"Applications of Energy Rate Techniques to Part-Through Cracks in Experimental Pressure Vessels"

ASME Journal of Pressure Vessel Technology, Vol. 104, p. 308, 1982.

19. LOSS, F. J., GRAY, R. A., and HAWTHORNE, J. R. "Significance of Warm Prestress to Crack Initiation During Thermal Shock," Report NRL/NUREG-8165, Naval Research Laboratory, NTIS, September 1977. 
Fig. 1. Six crack configurations automatically generated by ORMGEN

Fig. 2. Crack tip region generated by ORMGEN

Fig. 3. Special crack tip elements employed by ORMGEN

Fig. 4. Collapsed prism elements appropriate for nonlinear analysis

Fig. 5. Crack configuration before and after crack extension

Fig. 6. Virtual crack extension for calculating energy release rate $\mathrm{G}_{\mathrm{T}}$ for (a) uniform and (b) local extension

Fig. 7. Schematic view of vessel $\mathrm{V}-8 \mathrm{~A}$

Fig. 8. Description of ITV V-8A cylinder analyzed showing crack and quarter cylinder as modeled.

Fig. 9. Detail of finite element model of intermediate test vessel

Fig. 10. Uniaxial stress-strain curve for intermediate test vessel $\mathrm{V}-8 \mathrm{~A}$ material

Fig. 11. J vs $\phi$ and $p$ for case V8EP9 $(a=98 \mathrm{~mm}, b=740 \mathrm{~mm})$

Fig. 12. A comparison of power-law $J_{2}$ curve fit to characterization weld data and $J_{R}$ data for the $V-8 A$ special ${ }^{R}$ seam weld

Fig. 13. Schematic for determination of $J_{-}$-controlled crack depth and tearing instability pressure of a vessel

Fig. 14. Fracture surface (side B) developed during V-SA test. The ductile fracture surface is the relatively dark contiguous area bounded by the fatigue crack extension and the light-tone brittle fracture regions generated during posttest fracturing at ${ }^{-}-196^{\circ} \mathrm{C}$. 
Fig. 26. Ideally-plastic ligament model in an externally cracked cylinder

Fig. 27. Comparison of ligament analyses for PTS transient T1 of labie 4 at $t=6 \mathrm{~min}$

Fig. 28. Upper-shelf arrest analysis based on $\mathrm{J}_{\mathrm{R}}$-controlled tearing

Fig. 29. Test conditions and criteria for optimization of PTS test parameters

Fig. 30. Critical crack depth and $K_{\mathrm{T}}$ vs time for PTS transient $T 2$ of Table 4. Numbers in circtes refer to criterion numbers of Fig. $\hat{z} g$ 


\section{Table 1 Summary of HSST computer programs for fracture analysis}

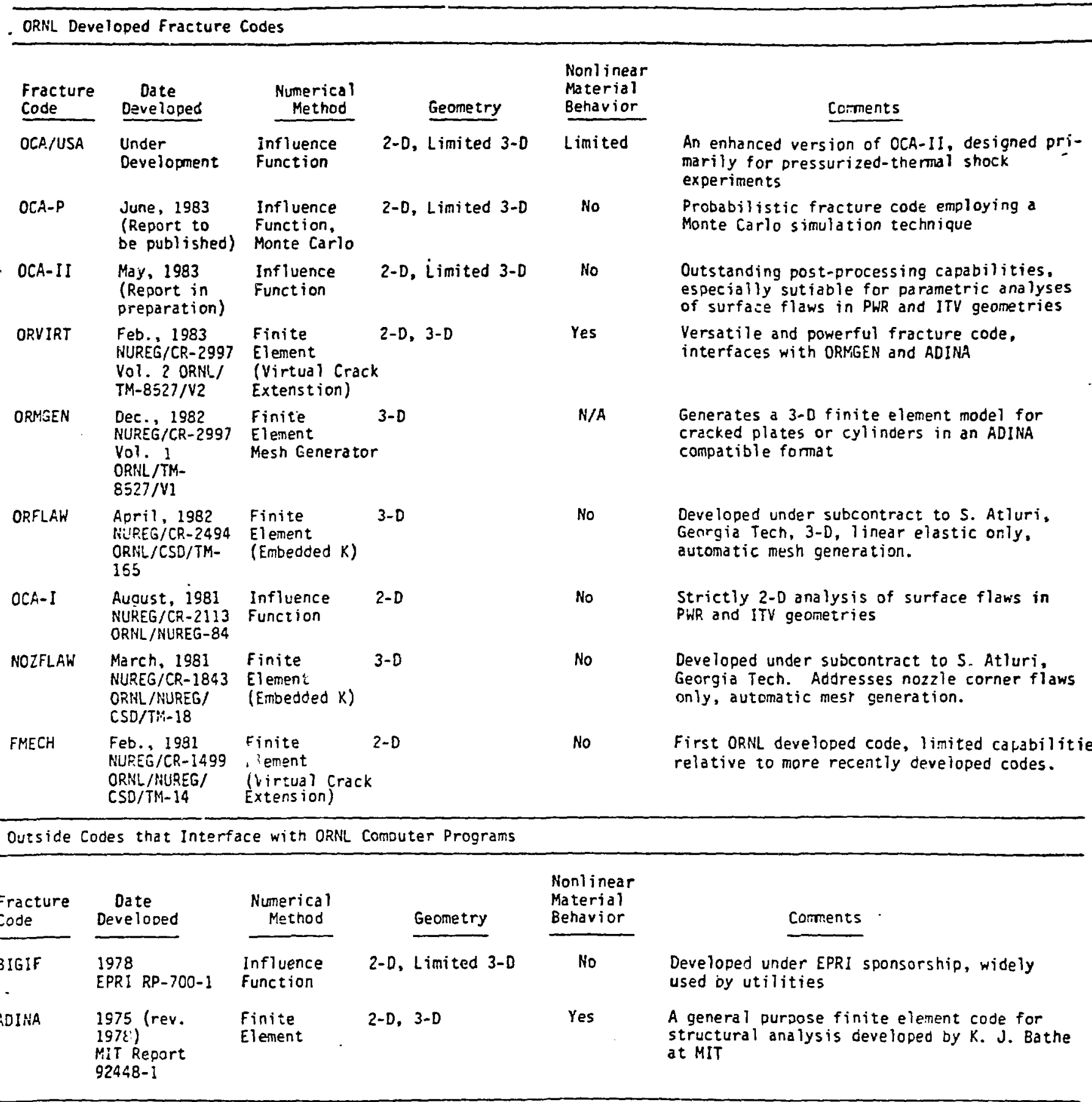


Table 2. Vessel V-8A pretest predictions for ductile crack instability

\begin{tabular}{|c|c|c|c|c|c|c|c|}
\hline & \multirow[t]{2}{*}{ Organization } & \multirow[t]{2}{*}{ Method } & \multicolumn{2}{|c|}{ Pressure } & \multirow{2}{*}{$\begin{array}{c}\text { Outside } \\
\text { Circumferential } \\
\text { Strain }\end{array}$} & \multicolumn{2}{|c|}{ a } \\
\hline & & & $(\mathrm{MPa})$ & (psi) & & $(\mathrm{mm})$ & (in.) \\
\hline 1. & $\begin{array}{l}\text { Nat, Bureau of Stds.. } \\
\text { Boulder, Co }\end{array}$ & $\begin{array}{l}\text { Simplified Line } \\
\text { Spring }\end{array}$ & 153 & 22,200 & 0.126 & 11.9 & 0.47 \\
\hline 2. & ORNL - A & Tangent Modulus & 150 & 21,700 & 0.133 & 10.2 & 0.40 \\
\hline 3. & IWM, Freiburg & (not specified) & 147.4 & $2 i, 379$ & & 15.0 & 0.59 \\
\hline 4. & ORNL - B & ORVIRT & 147 & 21,321 & & 10.0 & 0.39 \\
\hline 5. & CERL (UK) & $\mathrm{RG}$ & 141 & 20,450 & & 7.0 & 0.28 \\
\hline 6. & ORNL - C & ORVIRT & 139 & 20,160 & & 8.0 & 0.31 \\
\hline 7. & AERE (UK) & $\mathrm{RG}$ & 128 & 18,560 & & 7.0 & 0.28 \\
\hline 8. & Nat. Nuclear (UK) & $\mathrm{RG}$ & 121 & 17,550 & 0.092 & 6.8 & 0.27 \\
\hline
\end{tabular}


Table 3. Crack geometry measurements

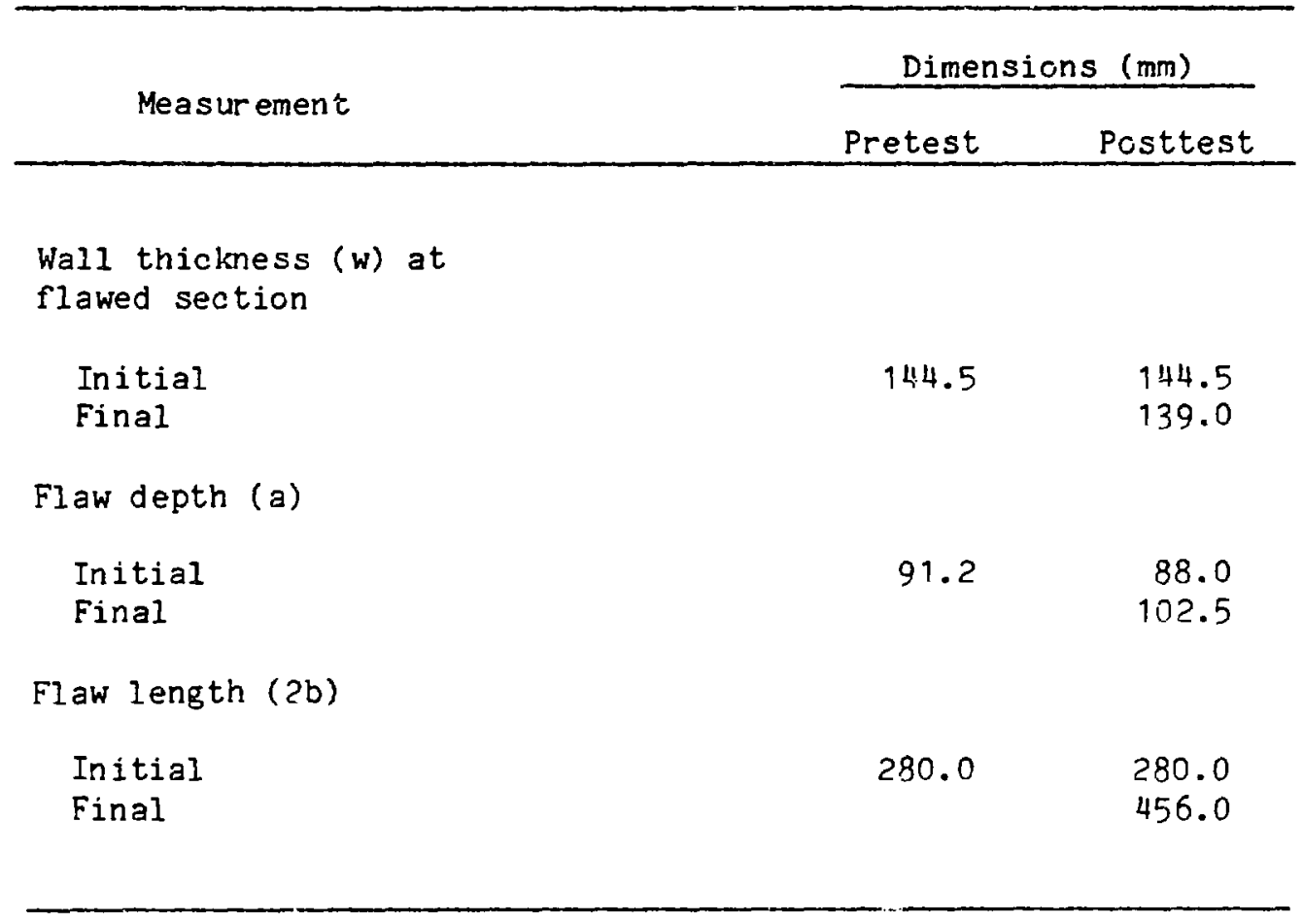


Table 4. PTS parameters for transients $\mathrm{T} 1$ and $\mathrm{T} 2$ used in the present study

\begin{tabular}{|c|c|c|c|c|c|}
\hline \multirow{3}{*}{$\begin{array}{c}\text { PTS } \\
\begin{array}{c}\text { transient } \\
\text { no. }\end{array} \\
\mathrm{T} 1 \\
\mathrm{~T} 2\end{array}$} & \multicolumn{5}{|c|}{ Constants } \\
\hline & $\begin{array}{c}\text { Initial } \\
\text { temperature } \\
\mathrm{T}_{0}\left({ }^{\circ} \mathrm{C}\right)\end{array}$ & \multicolumn{2}{|c|}{$\mathrm{RT}_{\mathrm{NDT}}\left({ }^{\circ} \mathrm{C}\right) \quad \mathrm{T}_{\mathrm{D}}\left({ }^{\circ} \mathrm{C}\right)$} & \multicolumn{2}{|c|}{$\begin{array}{l}\text { Heat transfer } \\
\text { coefficjent } \\
\quad h\left(\mathrm{wm}^{-2} \mathrm{k}^{-1}\right)\end{array}$} \\
\hline & $\begin{array}{l}191 \\
290\end{array}$ & $\begin{array}{l}13 \\
52\end{array}$ & $\begin{array}{l}120,130 \\
170\end{array}$ & $\begin{array}{l}5675 \\
5675\end{array}$ & \\
\hline \multirow[b]{2}{*}{$\begin{array}{l}\text { Time } \\
(\min )\end{array}$} & \multicolumn{4}{|c|}{ Variables (linear between time points) } & \multirow[b]{2}{*}{$\begin{array}{l}\text { (MPa) } \\
\mathrm{T} 2\end{array}$} \\
\hline & $\begin{array}{c}\text { Coolant ter } \\
T 1\end{array}$ & $\begin{array}{c}\text { perature } \\
\text { T2 }\end{array}$ & $\left.{ }^{\circ} \mathrm{C}\right)$ & $\begin{array}{l}\text { Pressure } \\
\quad \mathrm{T} 1\end{array}$ & \\
\hline 0 & -23 & 5 & & 27.6 & 0.5 \\
\hline 1 & - & - & & - & 0.5 \\
\hline 2 & - & - & & - & 15 \\
\hline 3 & - & . & & 27.6 & . \\
\hline 4 & - & . & & 20.7 & - \\
\hline 5 & . & - & & 48.3 & - \\
\hline 6 & - & - & & 82.7 & 10 \\
\hline 8 & . & . & & . & 50 \\
\hline 20 & 12 & 15 & & 82.7 & 50 \\
\hline
\end{tabular}




\section{om \\ SIX CRACK CONFIGURATIONS AUTOMATICALLY GENERATED BY ORMGEN}

PLATE

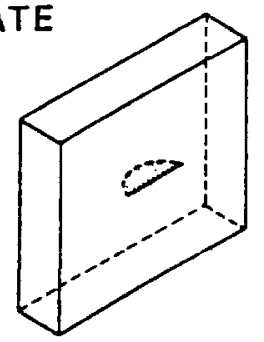

(a) CURVED

CYLINDER

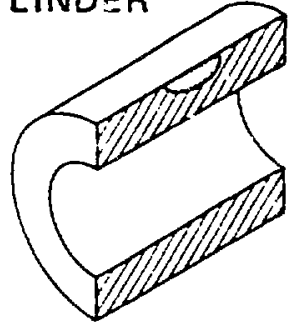

(c) CURVED CRACK ON OUTSIDE SURFACE

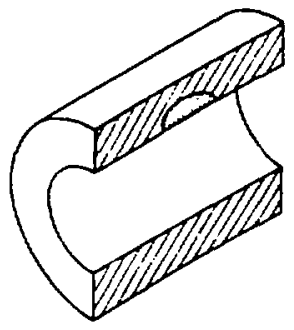

(e) CURVED CRACK ON INSIDE SURFACE

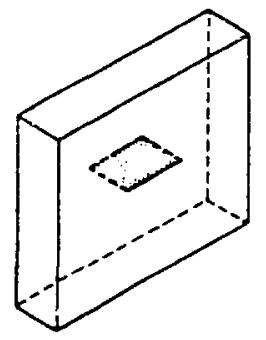

(b) STRAIGHT EDGE

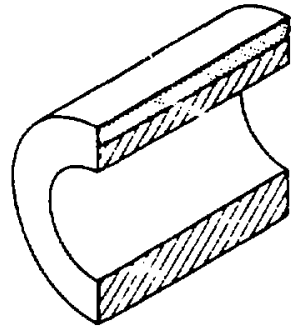

(d) STRAIGHT EDGE CRACK ON OUTSIDE SURFACE

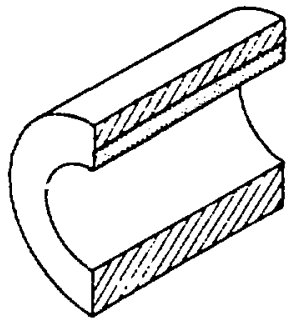

(f) STRAIGHT EDGE CRACK ON INSIDE SURFACE 


\section{ond}

\section{CRACK TIP REGION GENERATED BY ORMGEN}

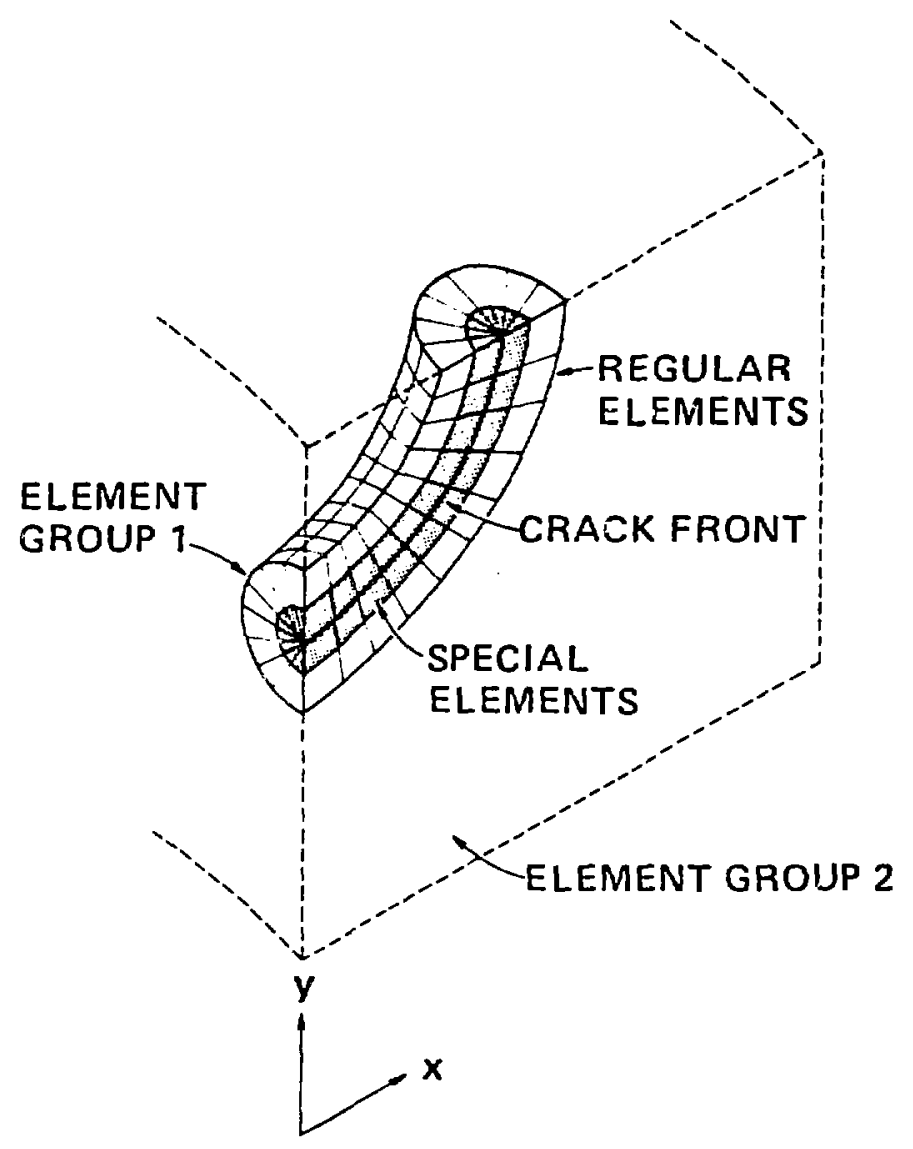

FIG. 2 


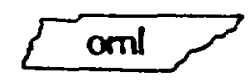

\section{SPECIAL CRACK TIP ELEMENTS EMPLOYED IN ORMGEN}

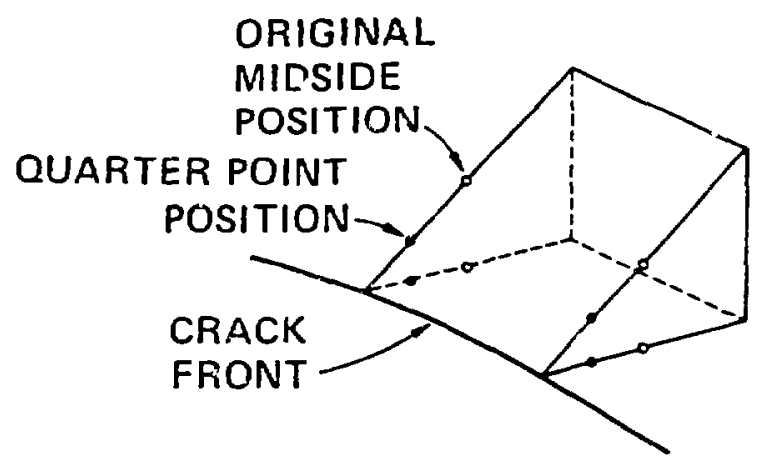

(a) DISTORTED WEDGE ELEMENT

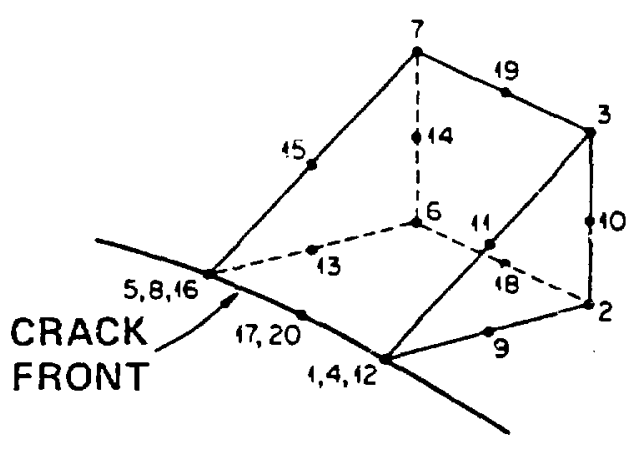

(b) 20-NODE WEDGE ELEMENT

FIG. 3 


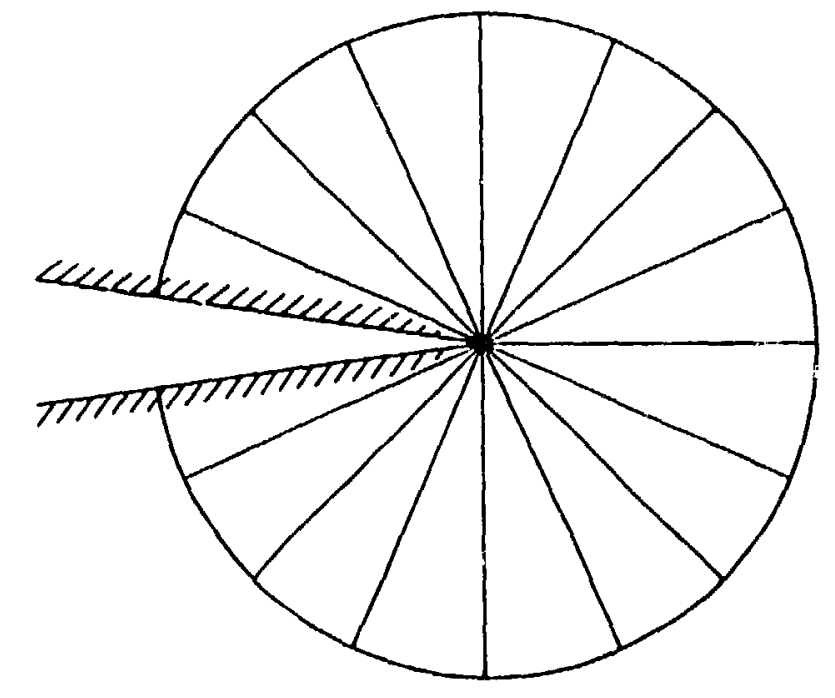

(a) ORIGINAL CONFIGURATION

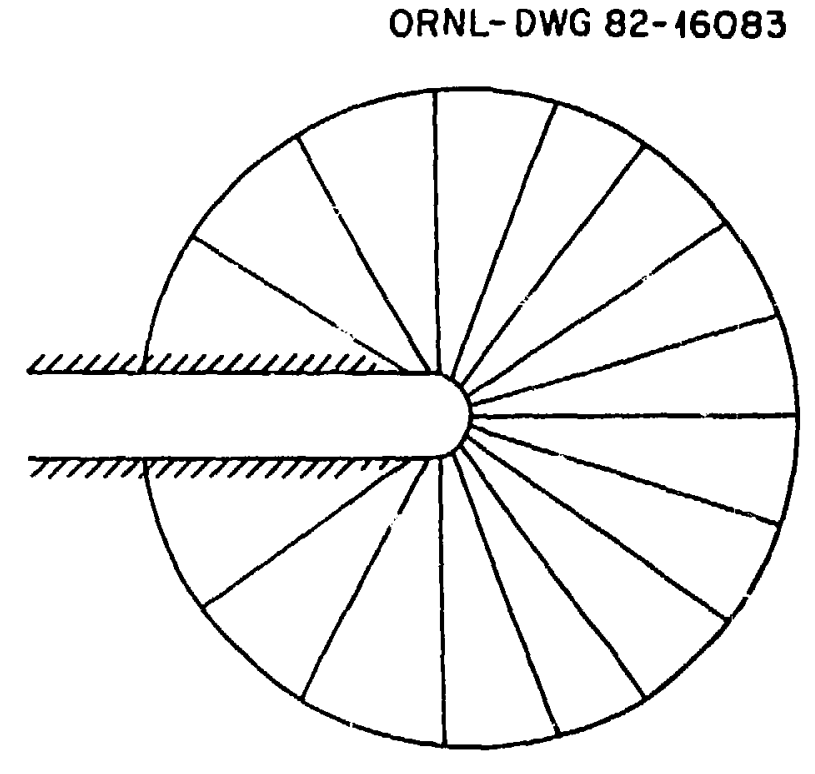

(b) DEFORMED CONFIGURATION

FIG. 4 
ORNL-DWG 82-8942
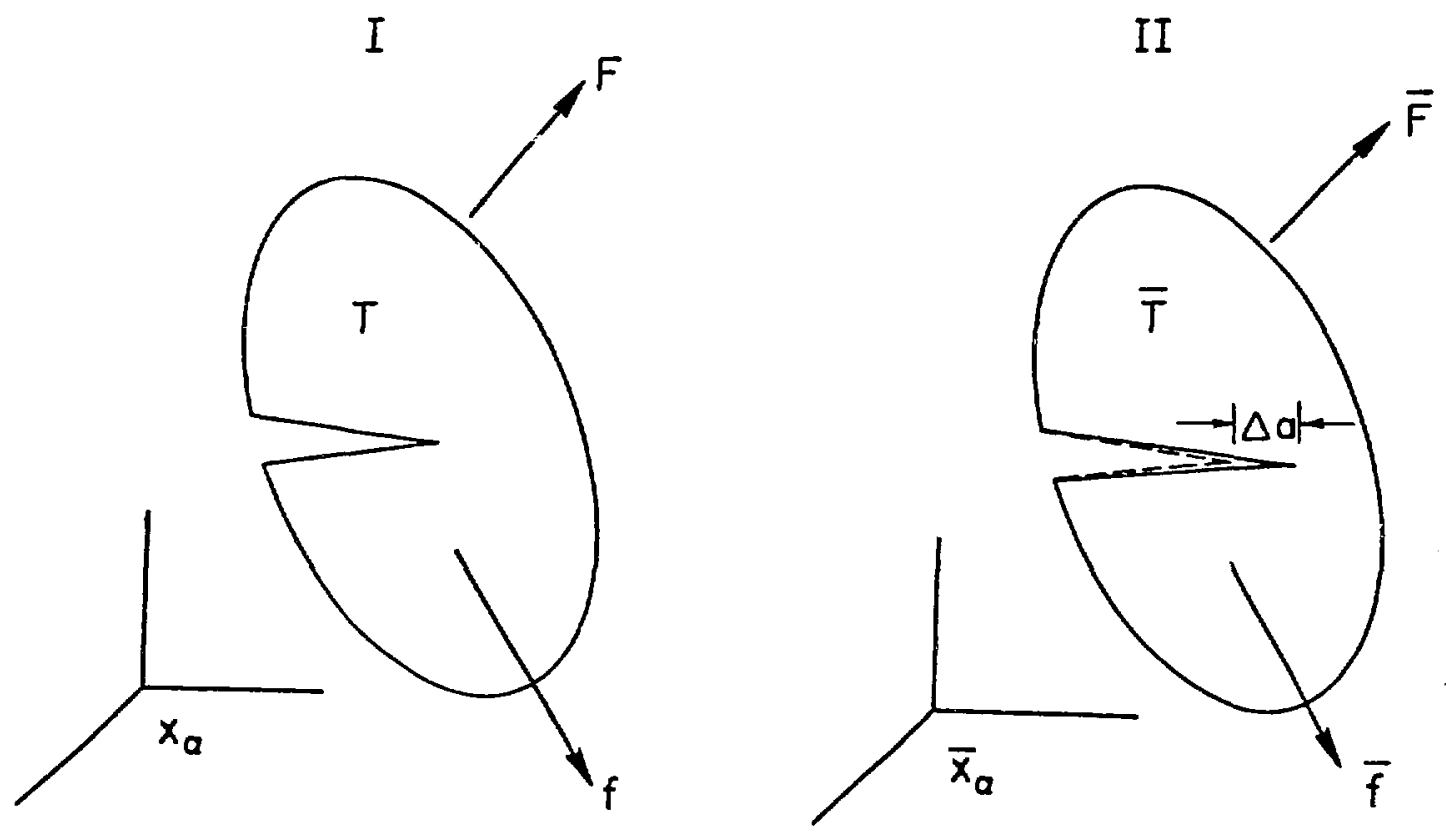

FIG. $S$ 
LOCAL AND UNIFORM ENERGY RELEASE RATES ARE COMPUTED FROM $G=G^{*} / \triangle A$

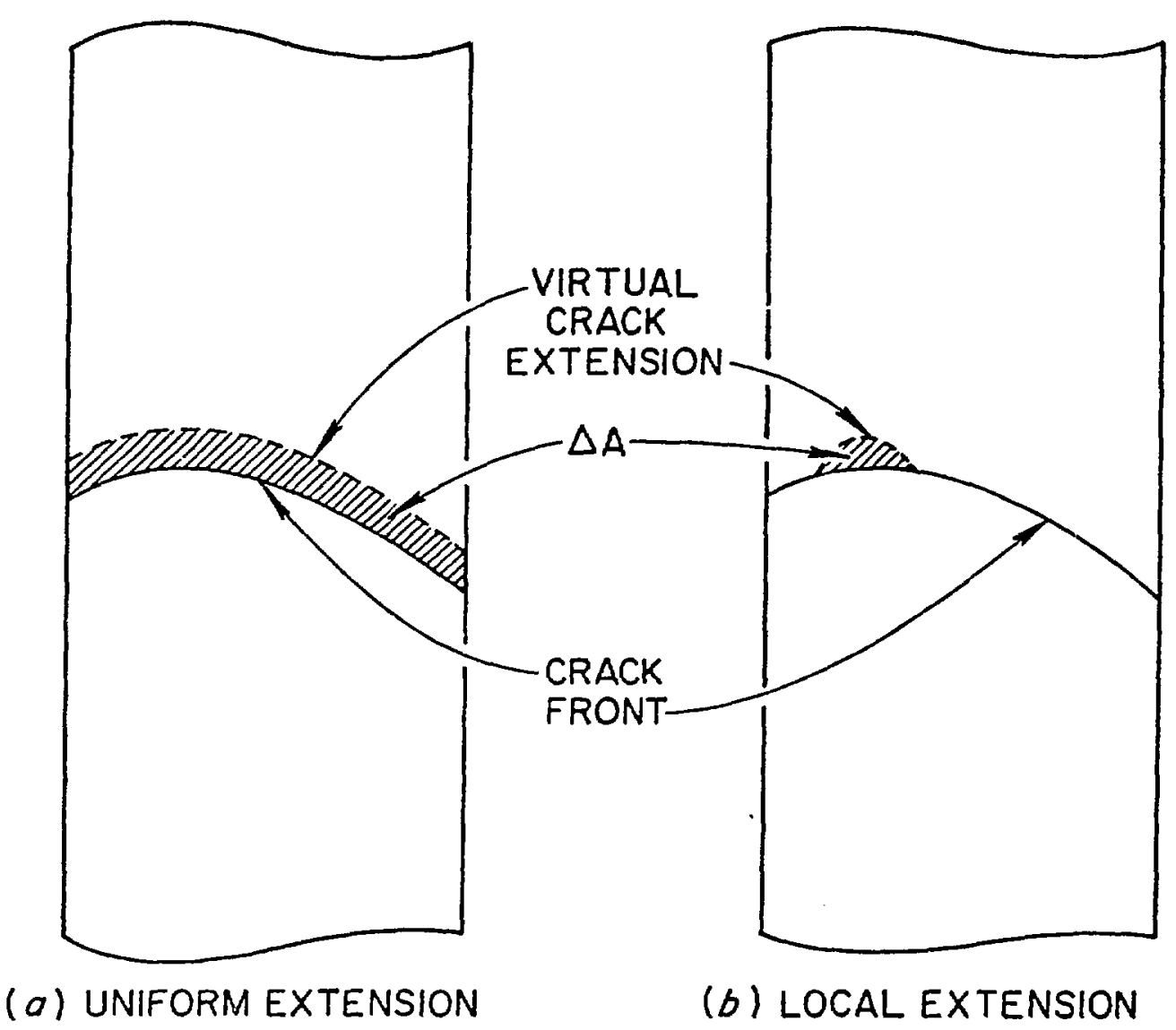

FIG. 6 


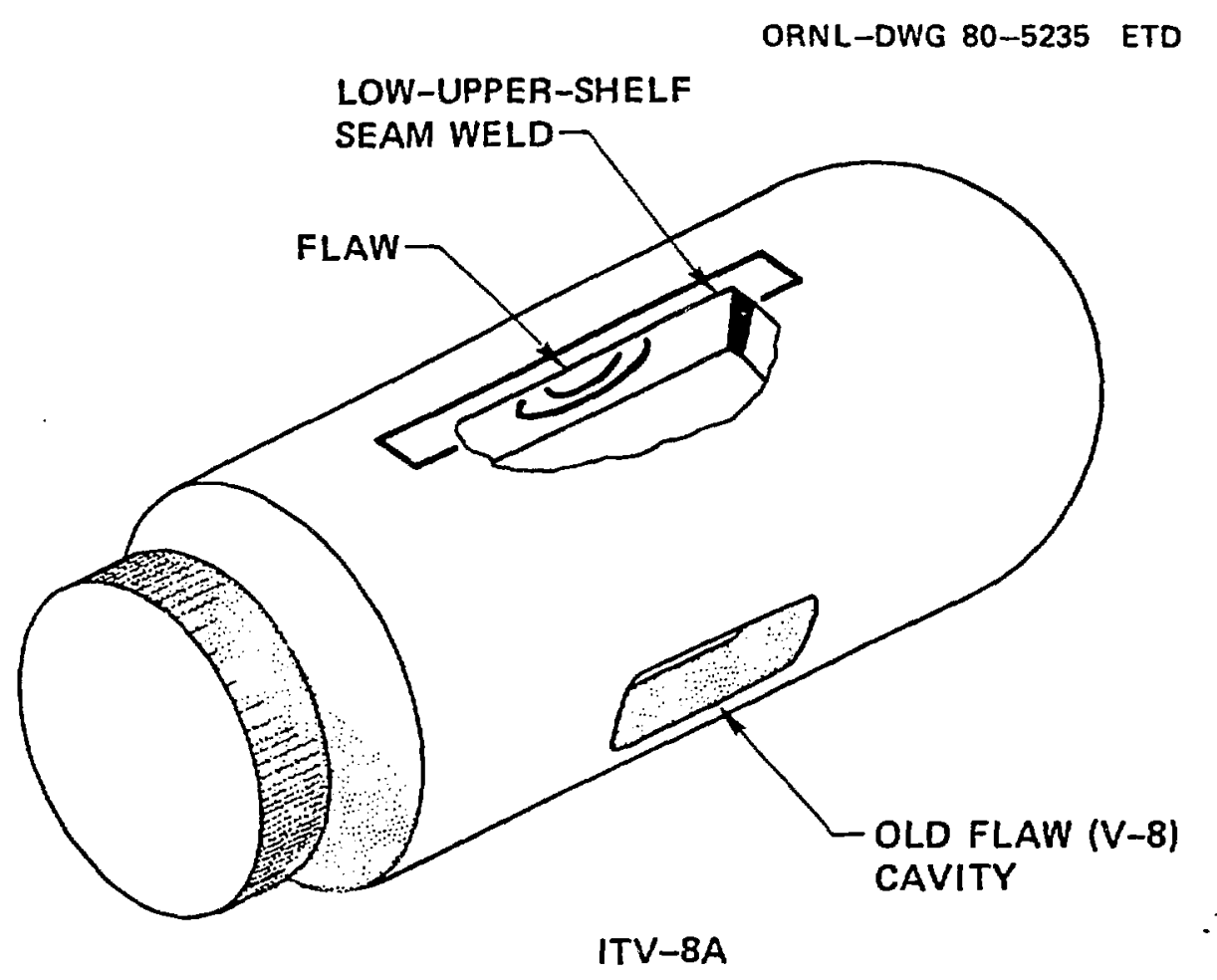

FIG.7 


\section{om}

\section{DESCRIPTION OF ITV V-8A CYLINDER ANALYZED SHOWING CRACK AND QUARTER CYLINDER AS MODELED}
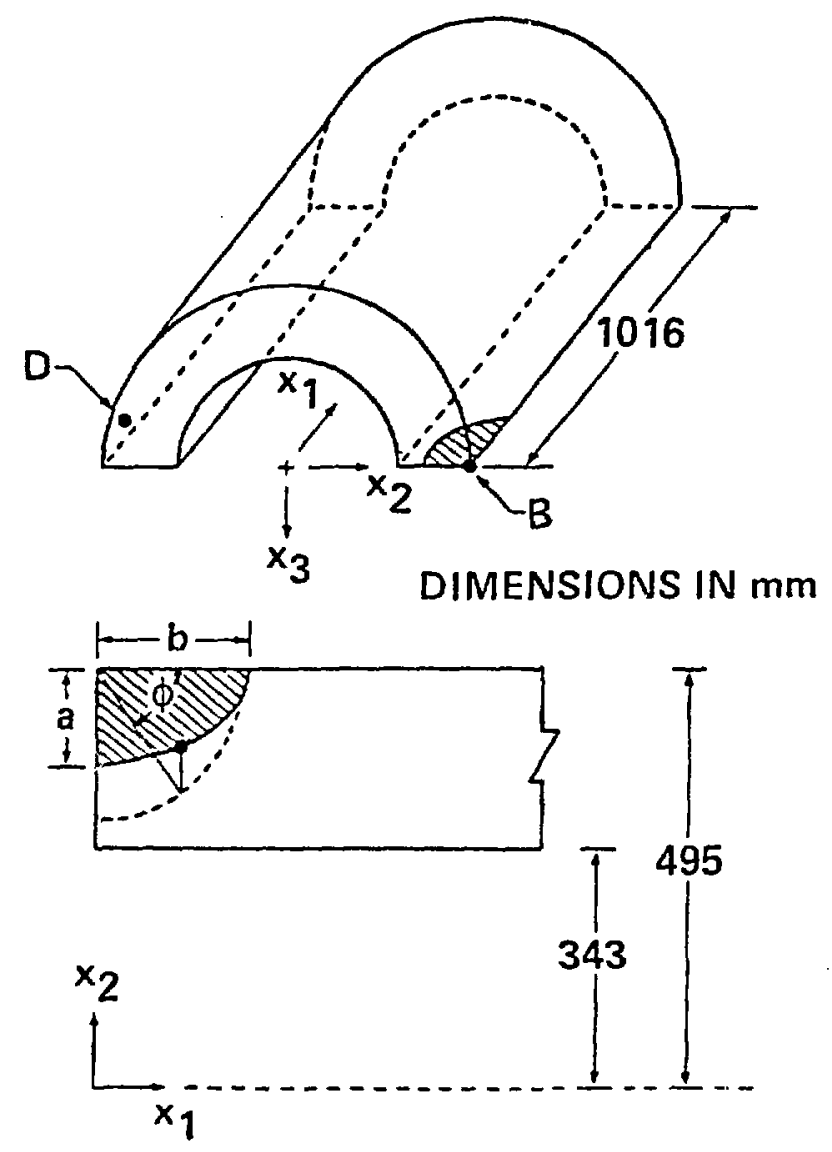

FIG. 8 

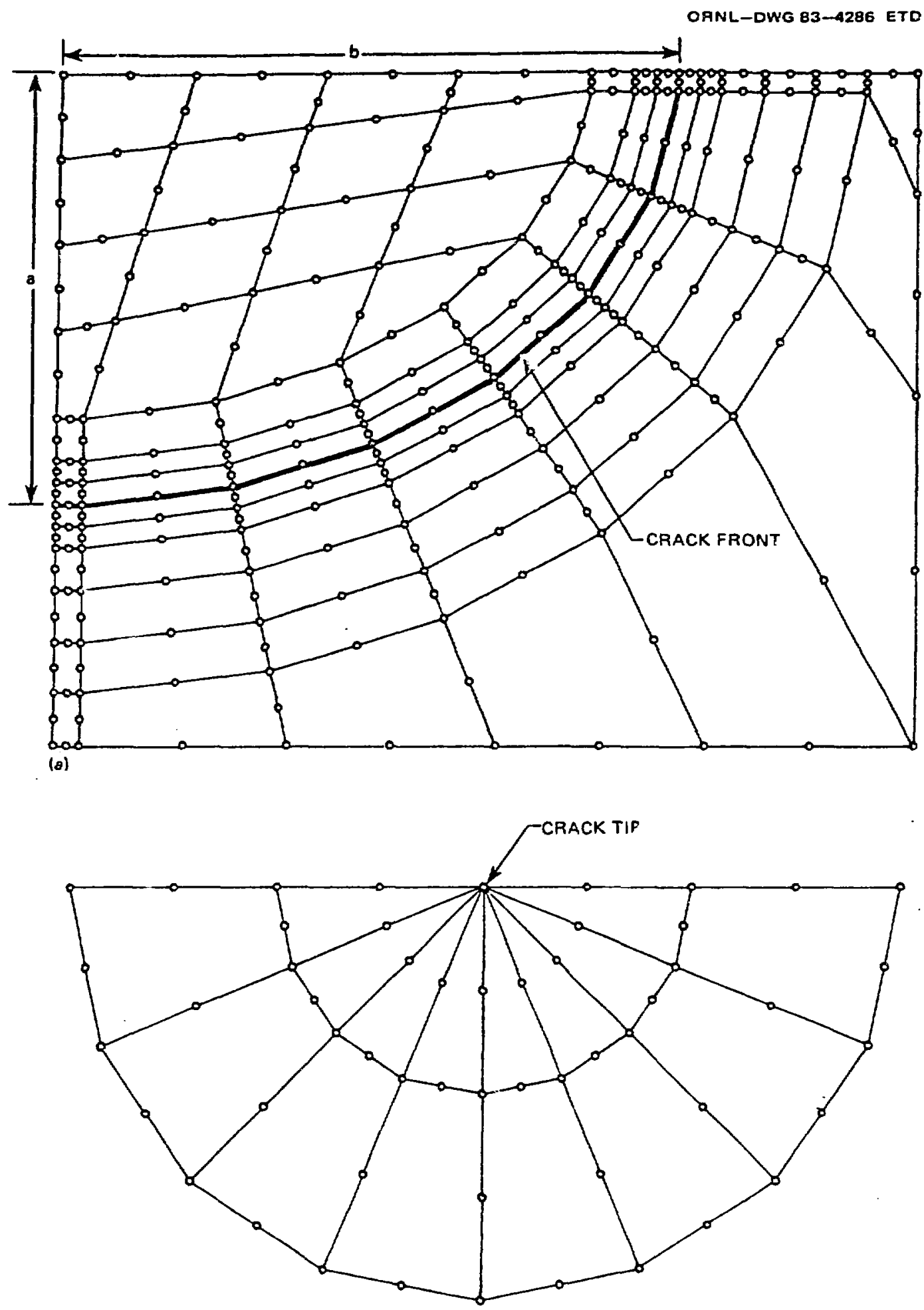

(b)

FIG. 9 


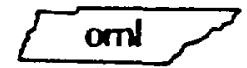

\section{UNIAXIAL STRESS-STRAIN CURVE FOR INTERMEDIATE TEST VESSEL $V-8 A$ MATERIAL}

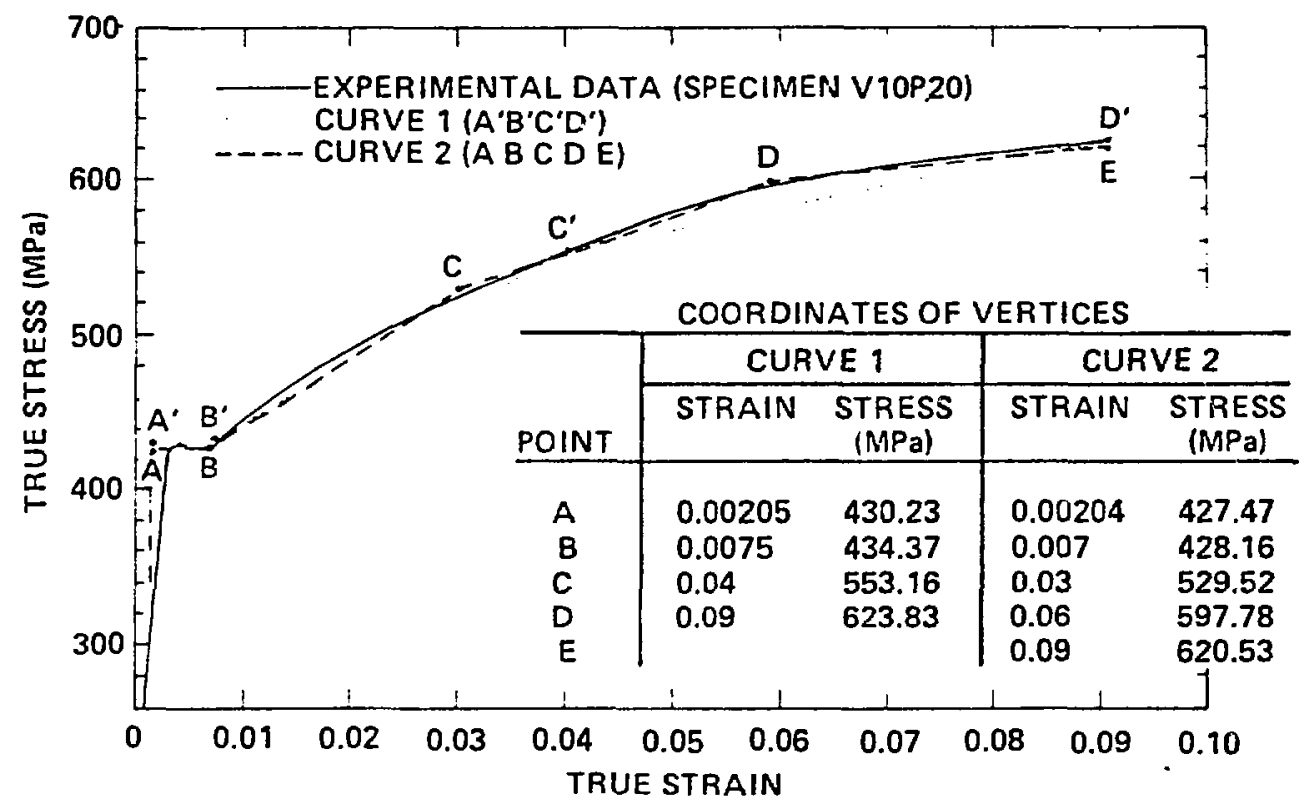

FIG. 10 


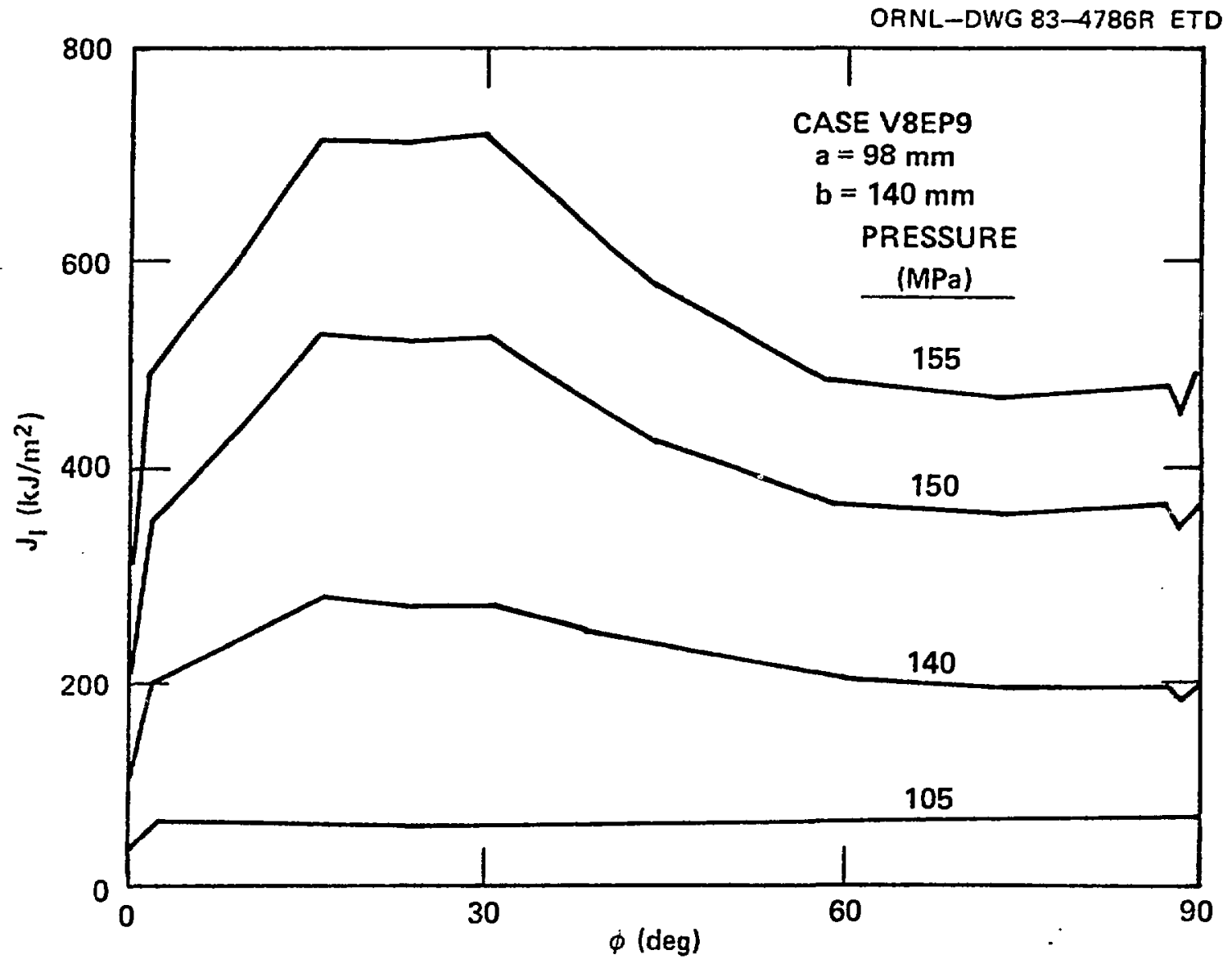

$F|G|$. 
ORNL-DWG 82-58:3B ETD

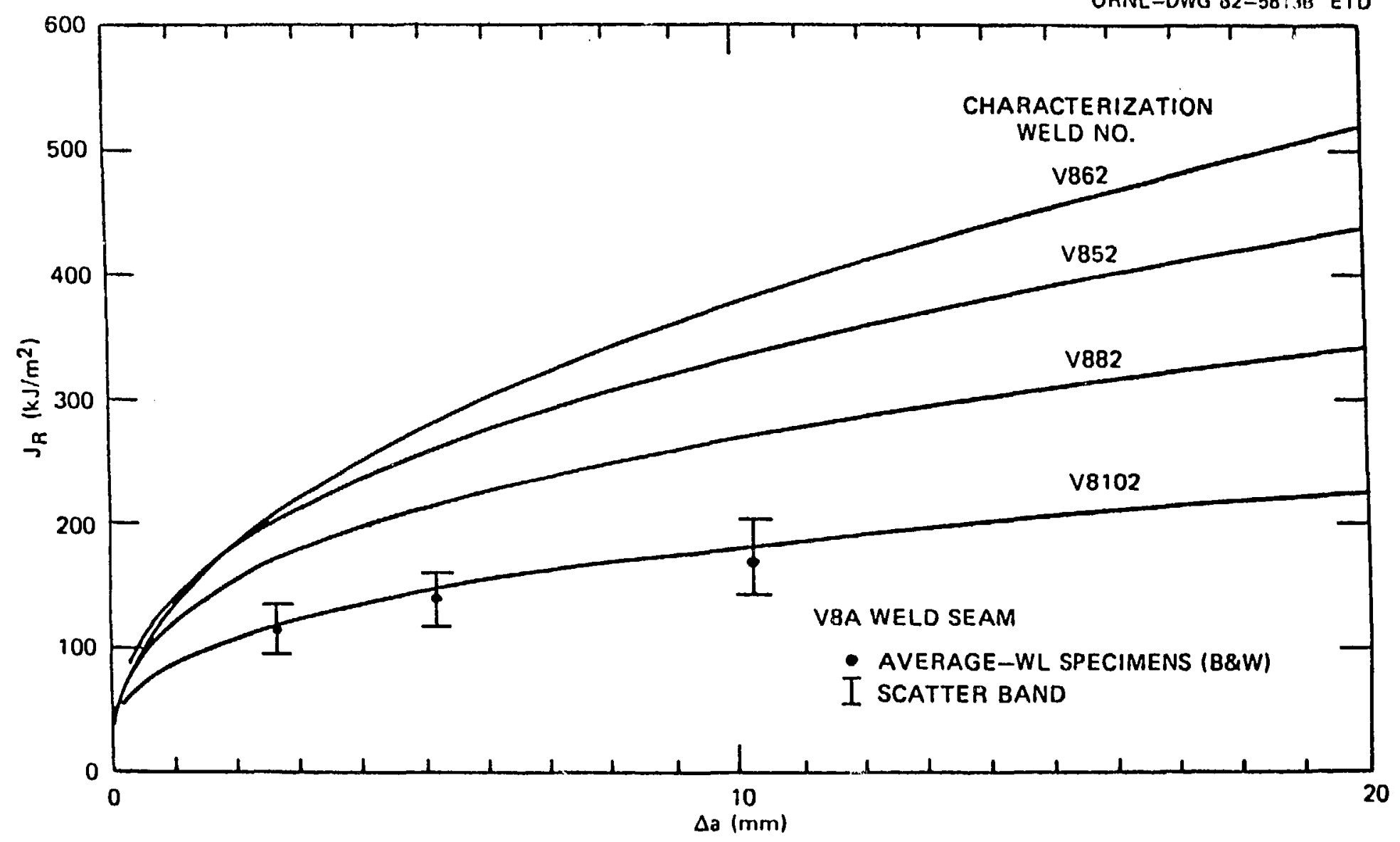

FIG. 12 


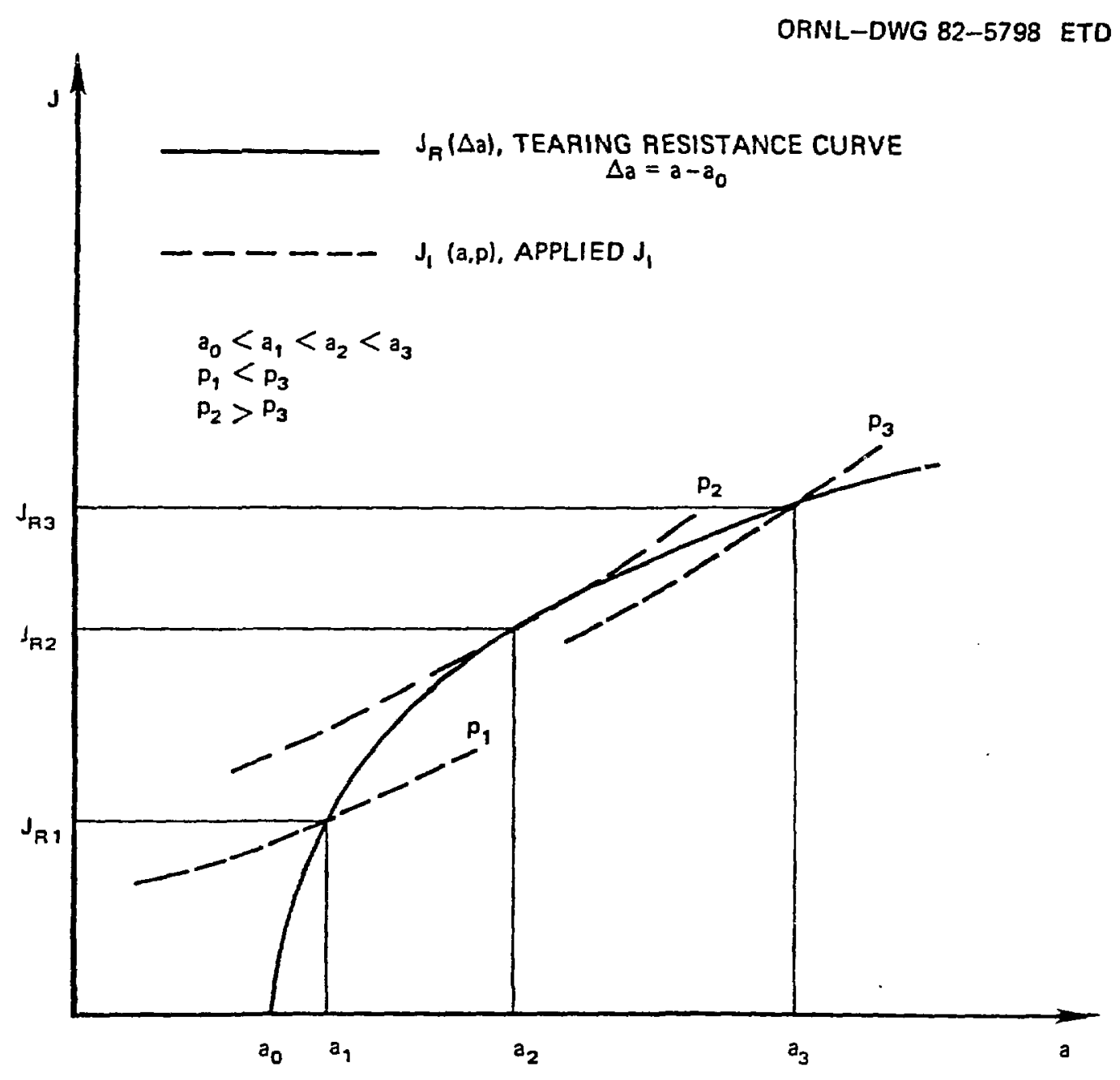

FIG.13 


\section{ornt}

FRACTURE SURFACE (SIDE B) DEVELOPED DURING V-8A TEST. THE DUCTILE FRACTURE SURFACE IS THE RELATIVELY DARK CONTIGUOUS AREA BOUNDED BY THE FATIGUE CRACK EXTENSION AND THE LIGHT-

TONE BRITTLE FRACTURE REGIONS GENERATED DURING POSTTEST FRACTURING AT $\sim-196^{\circ} \mathrm{C}$

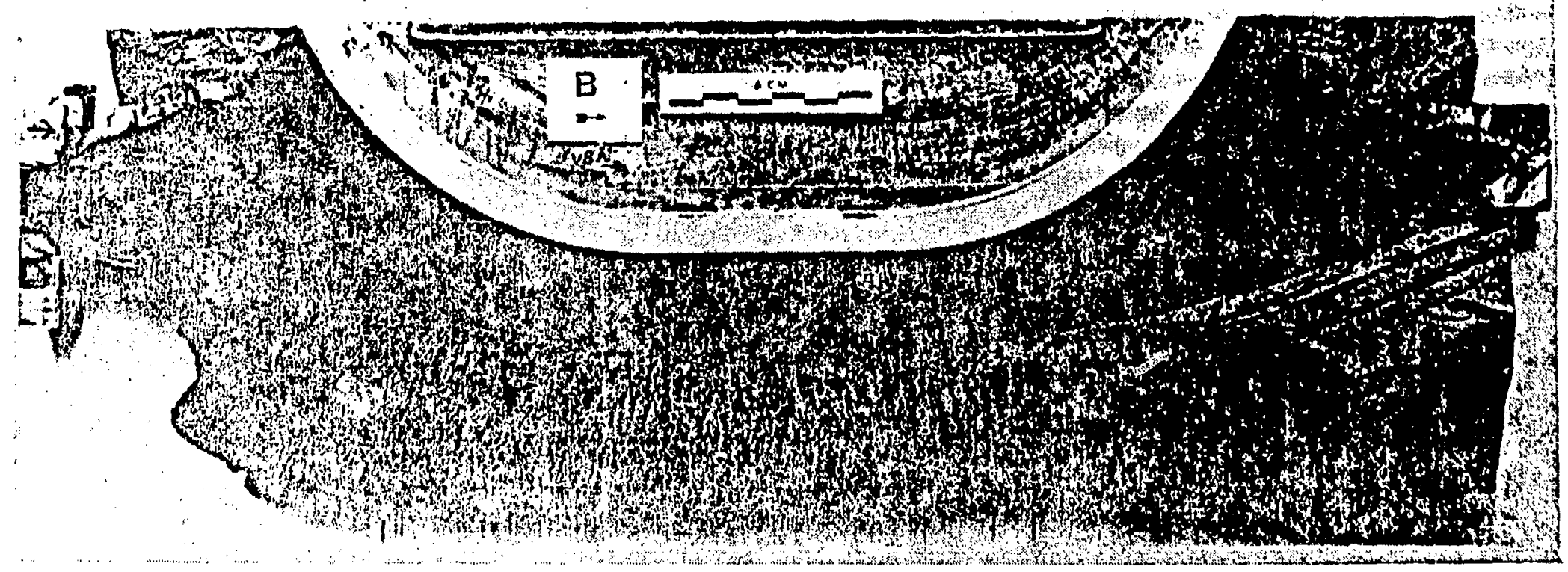




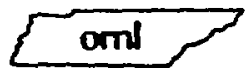

\section{FOUR CRACK PROFILES SUBJECTED TO POSTTEST ANALYSIS USING ORMGEN/ADINA/ORVIRT}

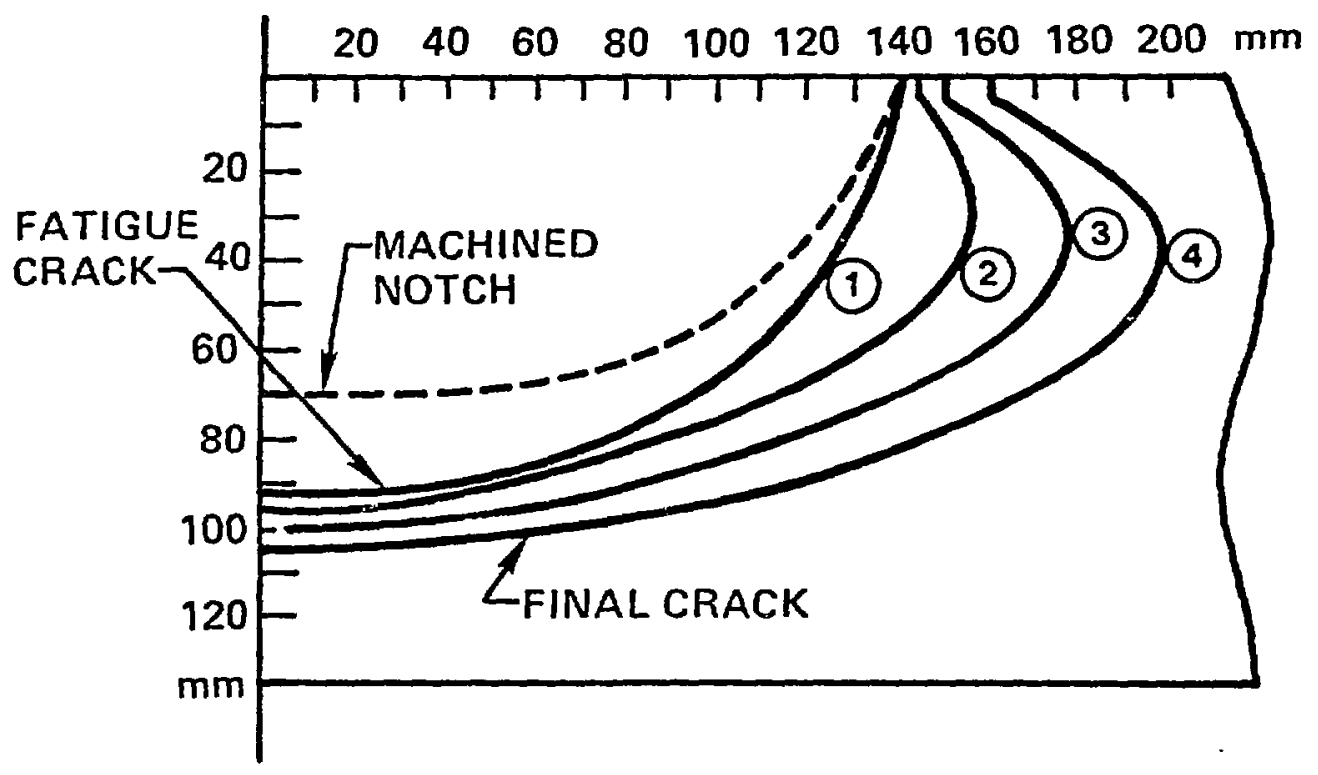


ORNL-DWG 83-5464 ETD

\section{onl}

\section{FINITE ELEMENT MODEL OF $\checkmark-8 A$ VESSEL}

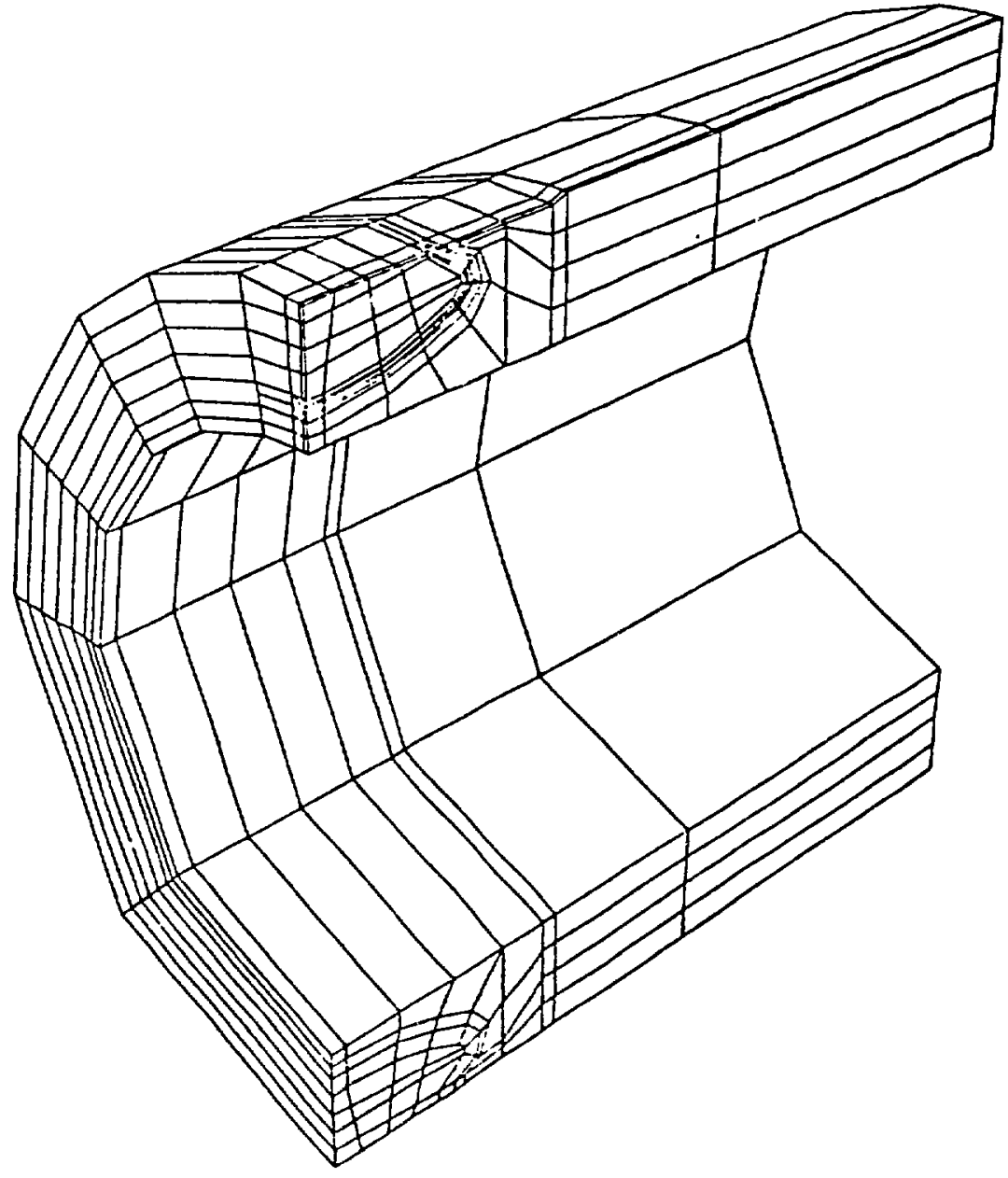

FIG. 16 

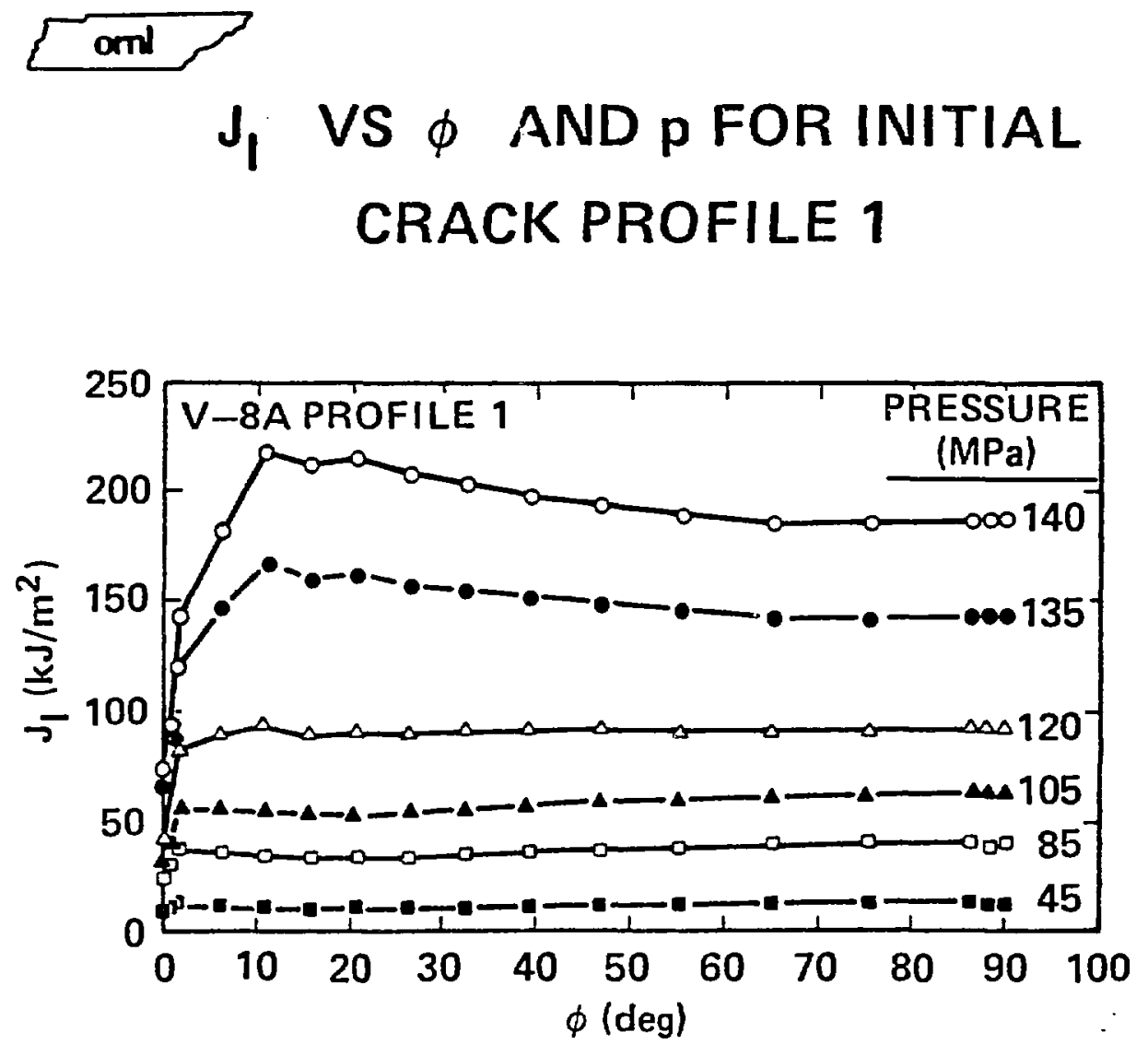


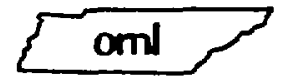

\section{$\mathrm{J}_{\mathrm{I}}$ VS $\phi$ AND $\mathrm{p}$ FOR INTERMEDIATE CRACK PROFILE 2}

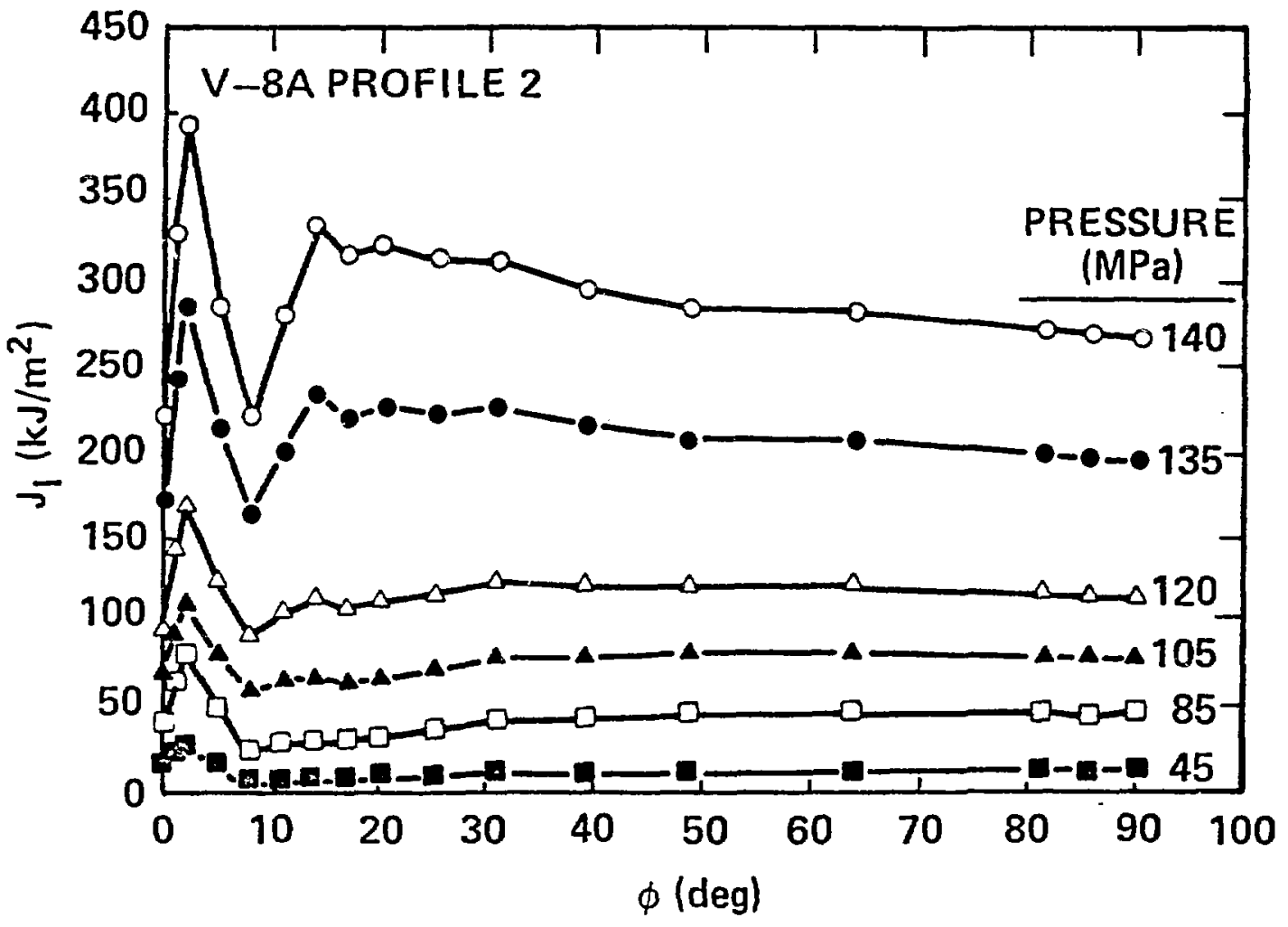




\section{oml \\ $J_{I}$ VS $\phi$ AND $p$ FOR INTERMEDIATE CRACK PROFILE 3}

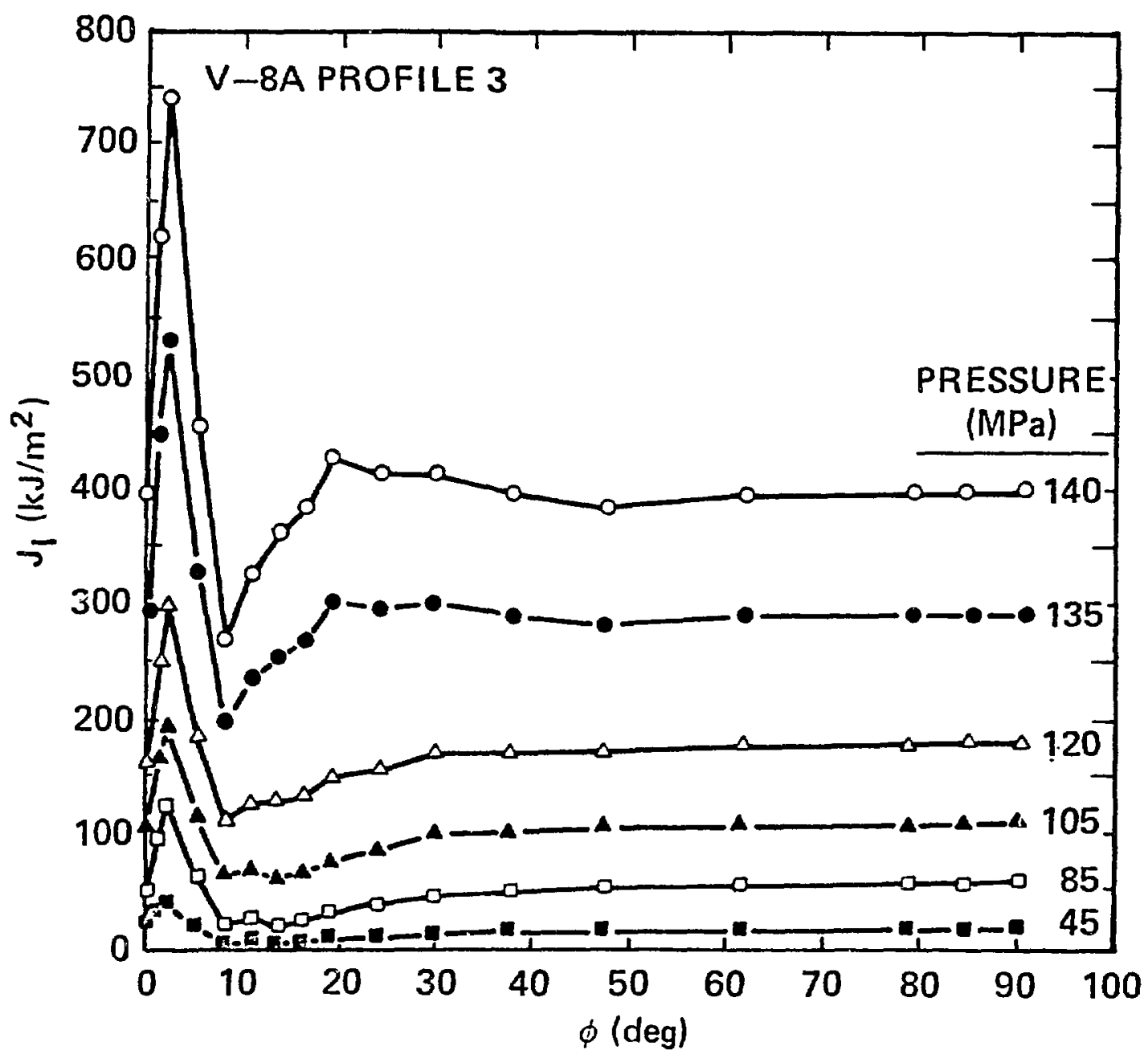

FlG. 19 
ORNL-DWG 83-5468 ETD

om

$J_{I}$ VS $\phi$ AND $p$ FOR FINAL CRACK PROFILE 4

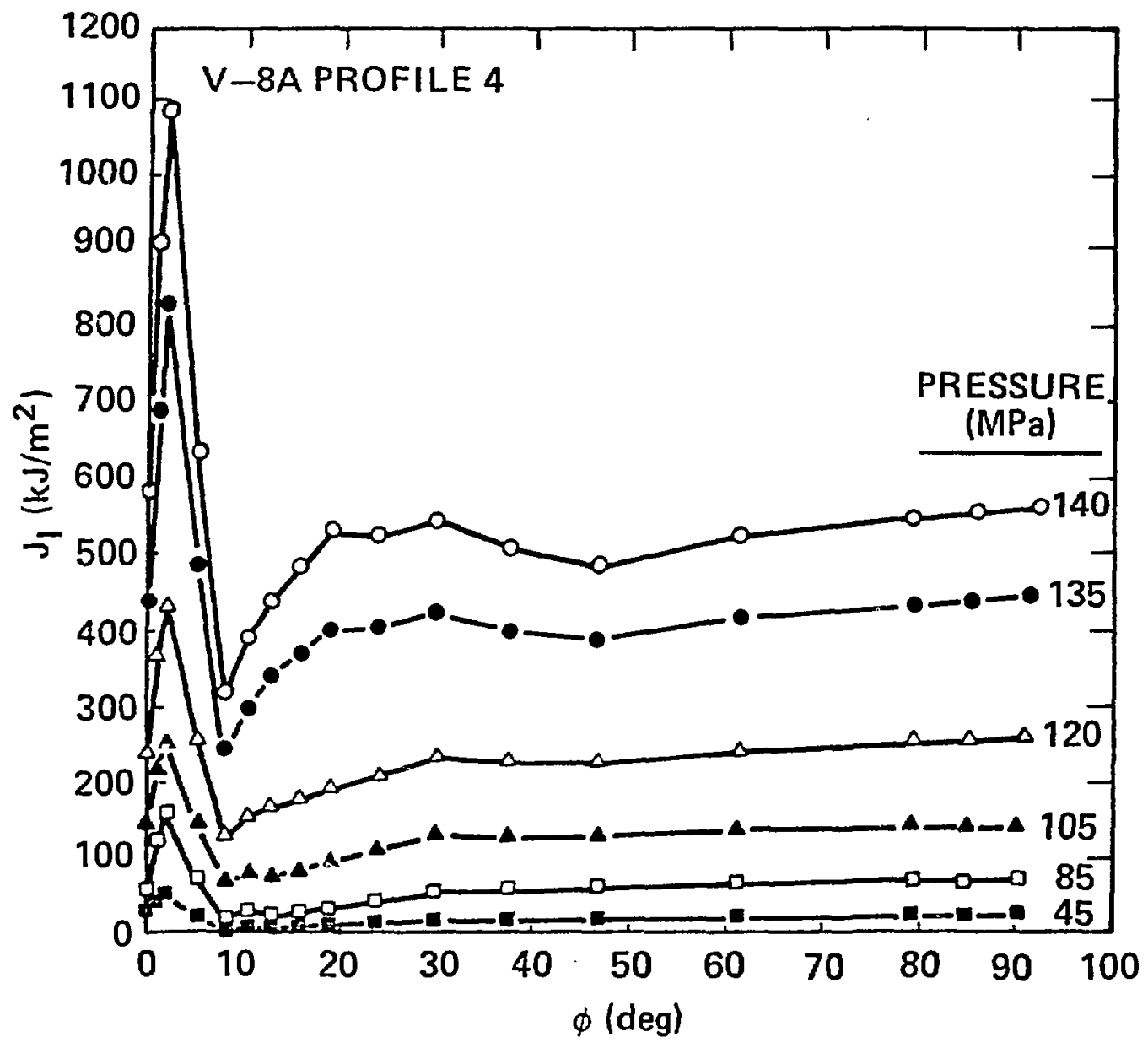

FIG. 20 

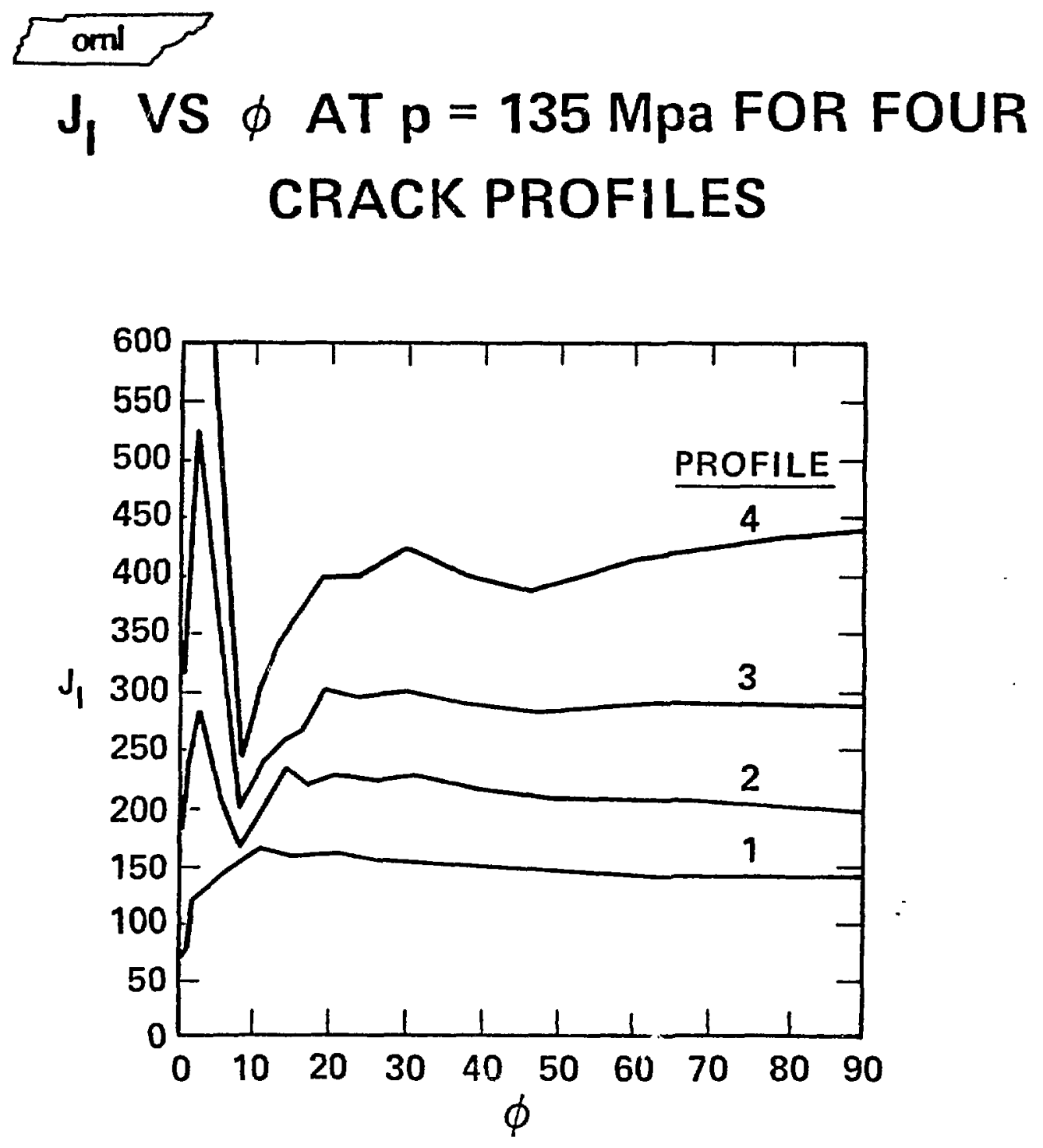

FIG. 21 
ORNL-DWG 83-5469 ETD

oml

\section{A COMPARISON OF MEASURED CMOD WITH COMPUTED CMOD FOR FOUR CRACK PROFILES}

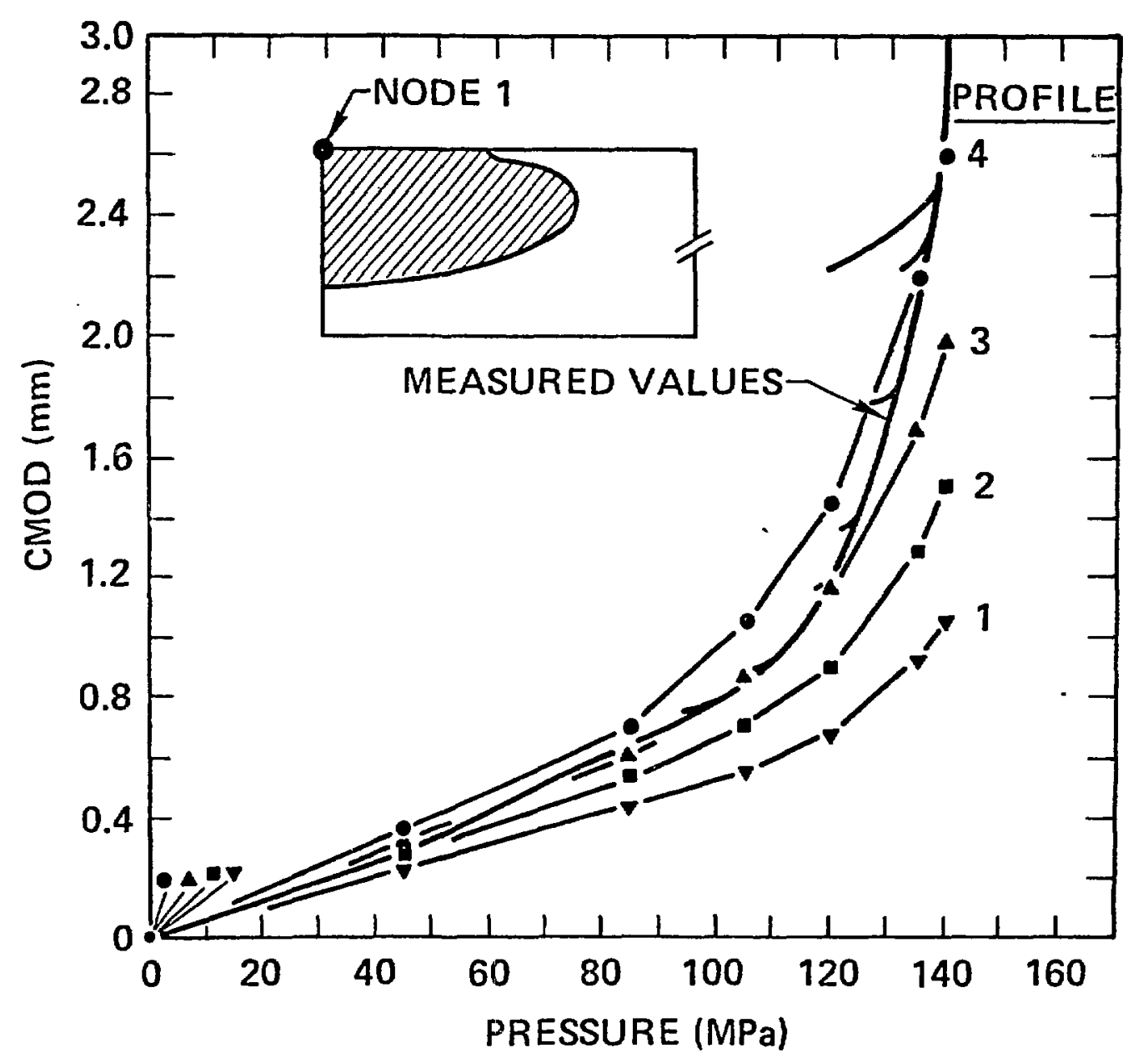

FIG. 22 


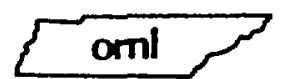

\section{PRESSURIZED-THERMAL-SHOCK TEST VESSEL WITH LONGITUDINAL OUTER SURFACE CRACK}

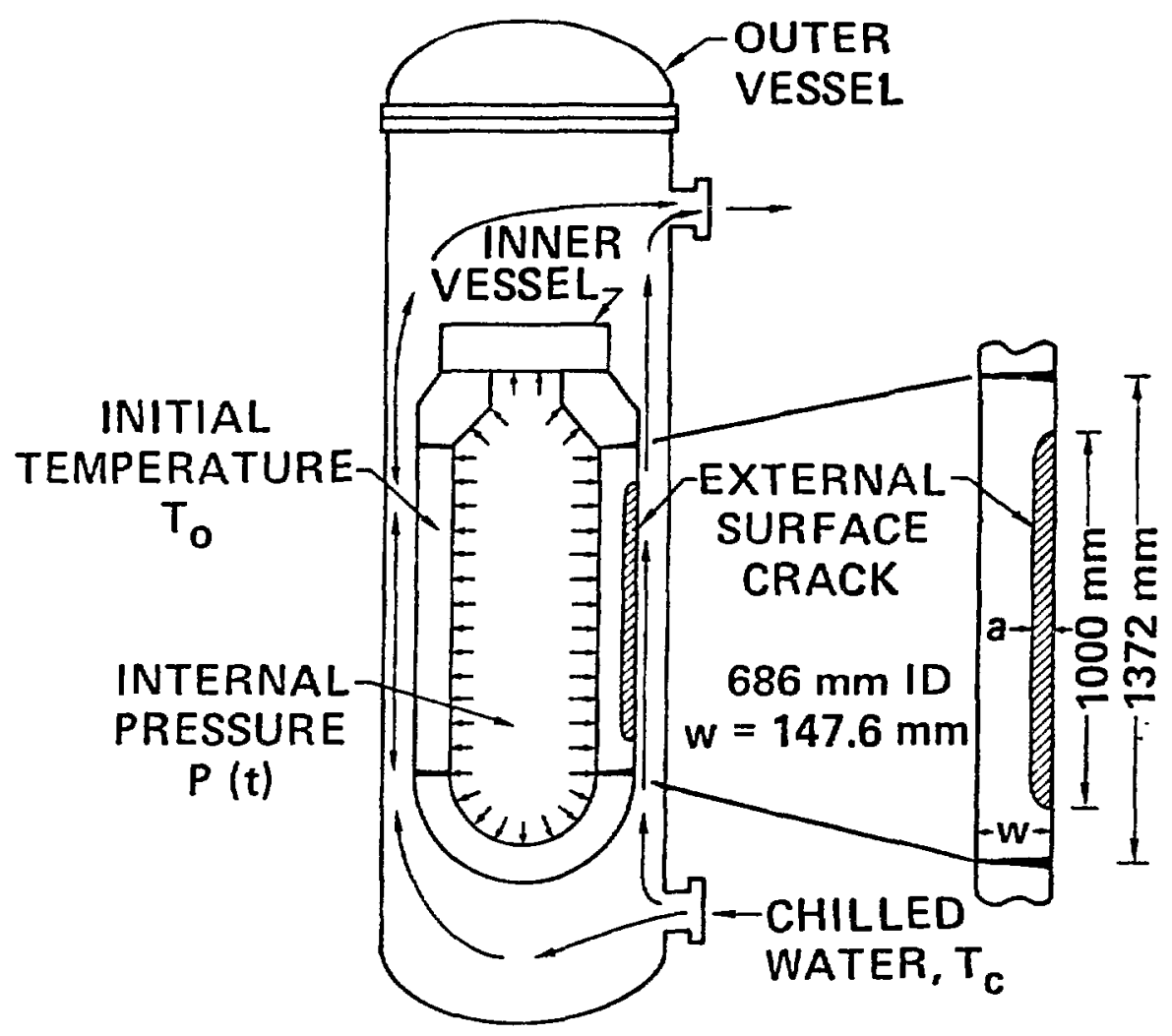

FlG. 23 


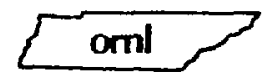

\section{SUPERPOSITION PRINCIPLE APPLIED TO A FINITE LENGTH SURFACE CRACK}

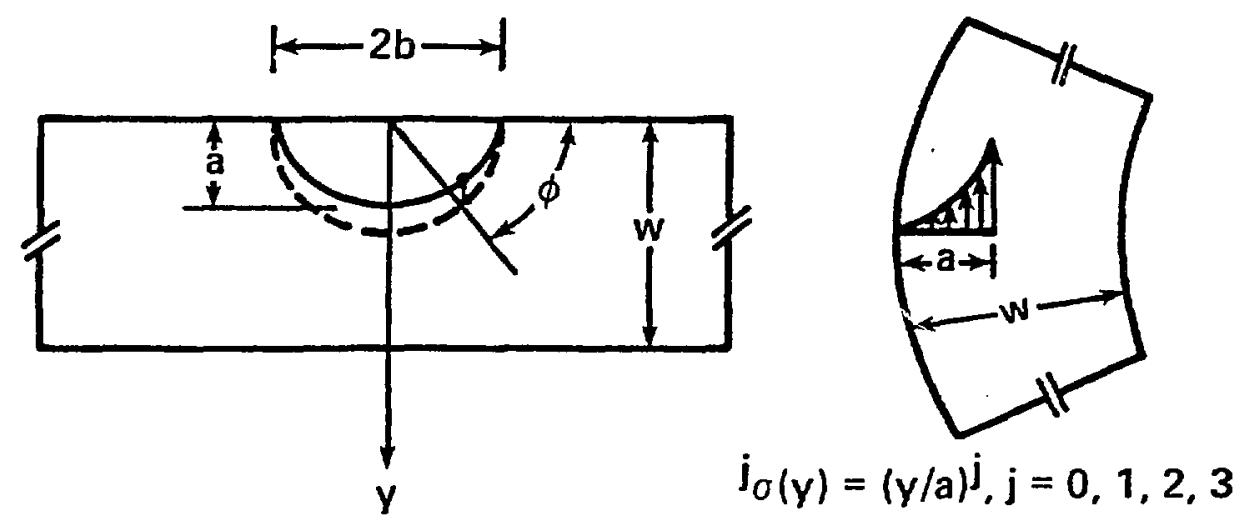

(a)

(b)

FIG. 24 


\section{om}

COMPARISON OF 3-D SUPERPOSITION WITH 3-D

DIRECT ANALYSIS FOR FINITE LENGTH SURFACE CRACKS FOR PTS TRANSIENT

T1 OF TABLE 4 AT $\mathrm{t}=6 \mathrm{~min}$

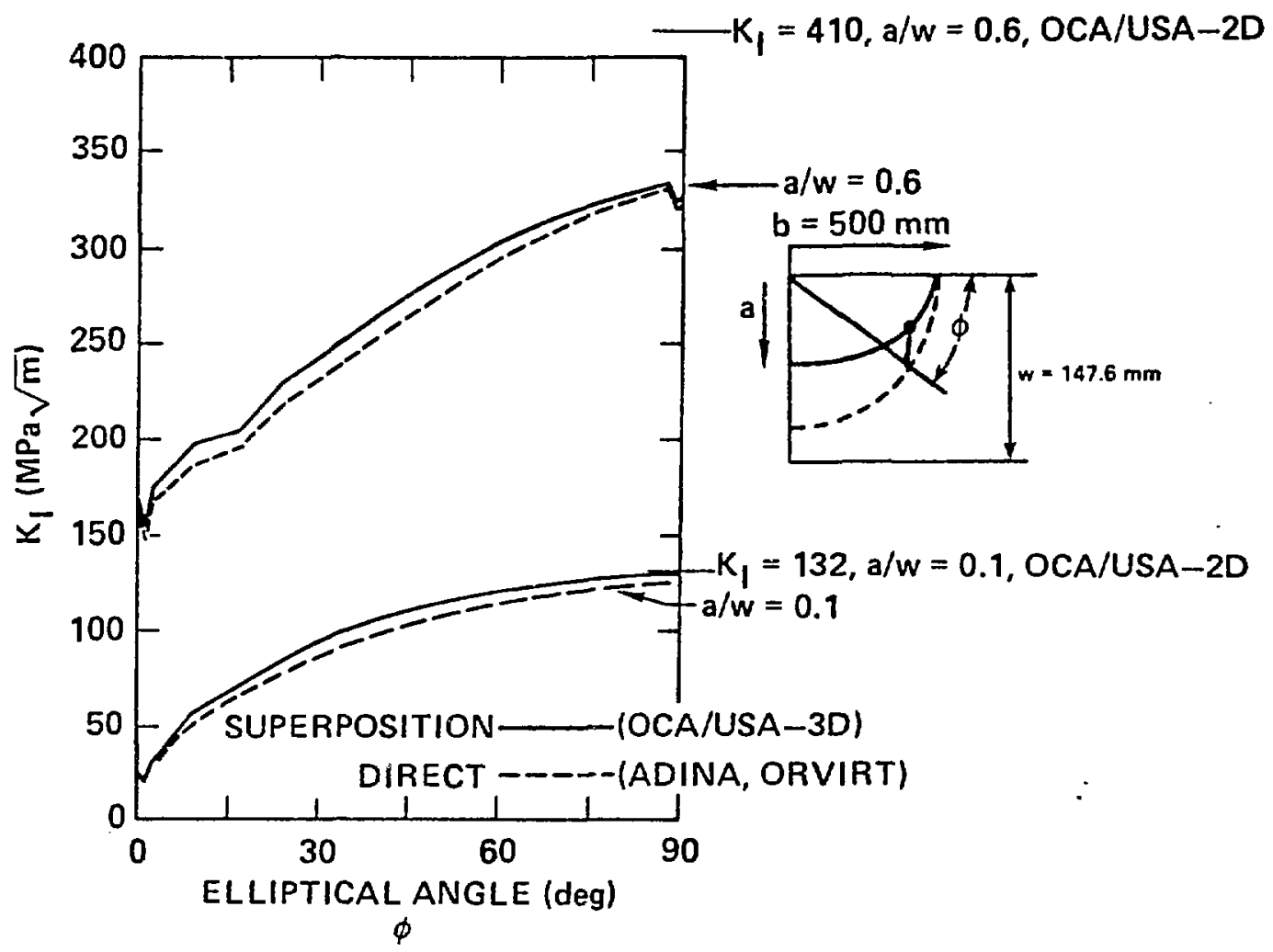


ORNL-DWG 83-4782 ETD

\section{AN IDEALLY PLASTIC LIGAMENT ANALYSIS IS PERFORMED FOR A DEEP CONTINUOUS EXTERNAL LONGITUDINAL CRACK IN A CYLINDER}

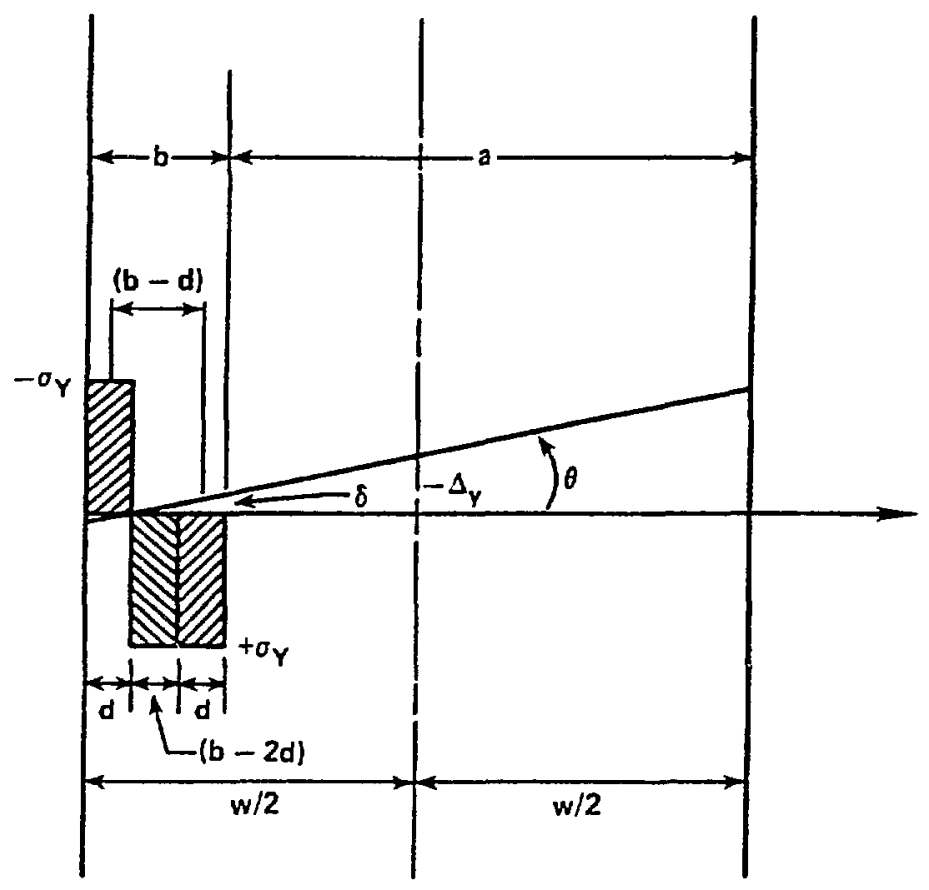




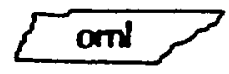

\section{COMPARISON OF LIGAMENT ANALYSES FOR PTS TRANSIENT T1 OF TABLE 4 AT $\mathrm{t}=6 \mathrm{~min}$}

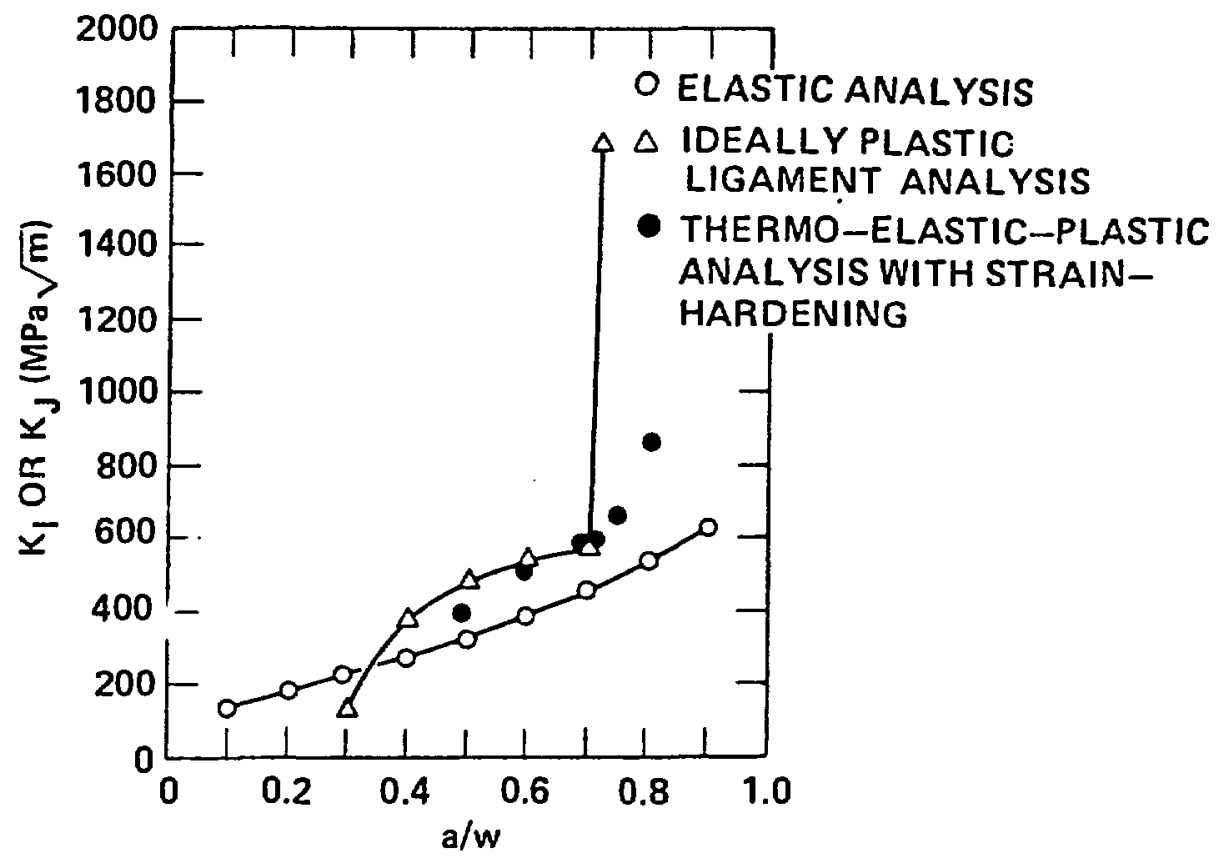


ORNL-DWG 83-4784A ETD

\section{ornl}

\section{UPPER-SHELF ARREST ANALYSIS BASED ON $J_{R}-$ CONTROLLED TEARING}

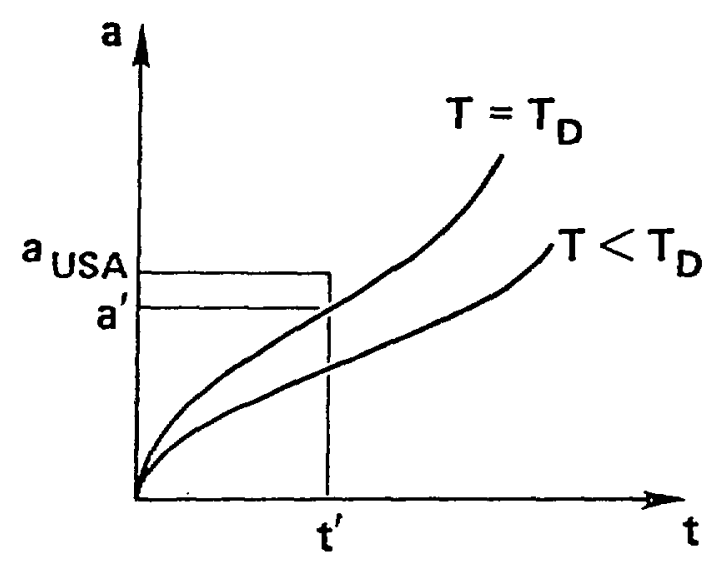

TEMPERATURE CONTOURS

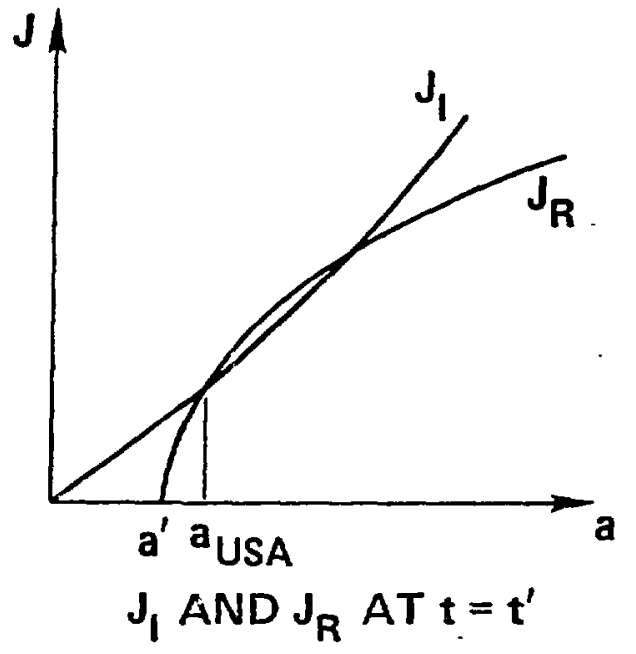




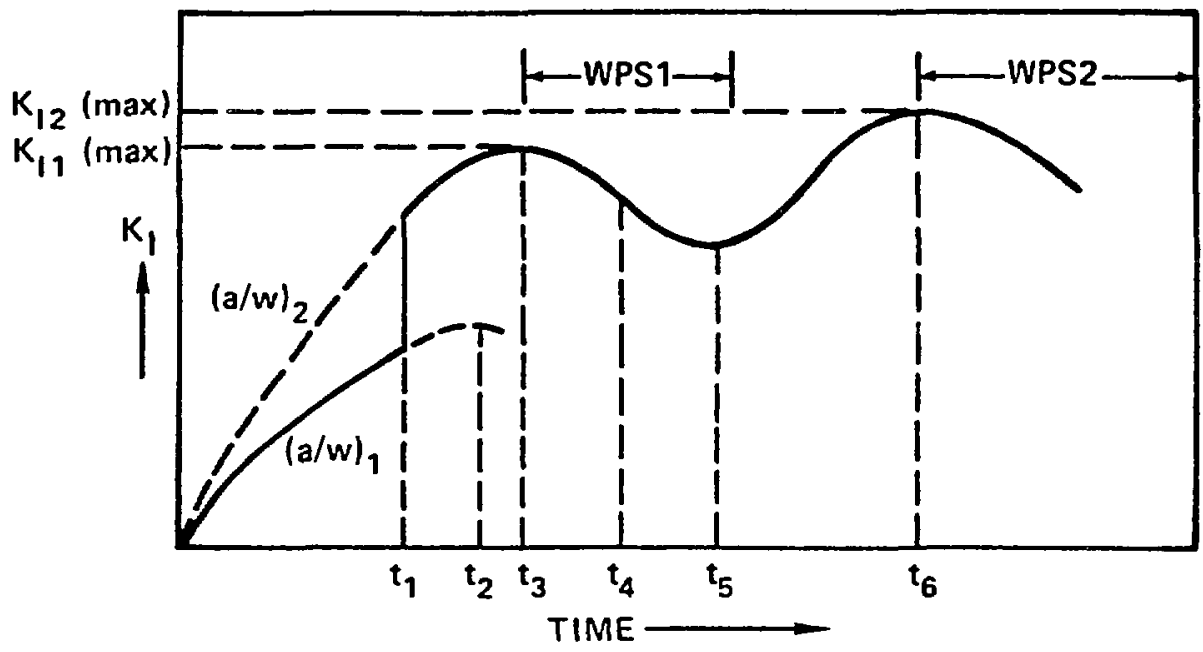

DEFINITIONS:
$(a / w)_{1}$
= INITIAL CRACK DEPTH
$(a / w)_{2}$
= CRACK DEPTH AT FIRST ARREST
$(a / w)$ USA
= CRACK DEPTH AT UPPER-SHELF ARREST
$(a / w)_{L I G}$
= CRACK DEPTH AT LIGAMENT INSTABILITY
$K_{11}(\max )$
$=K_{I}$ AT START OF WPS 1
$K_{12}(\max )$
$=K_{1}$ AT START OF WPS2
tusi
$=$ TIME OF UPPER-SHELF INSTABILITY

\section{CONDITIONS:}

$t_{1}: \quad K_{1} / K_{1 c}=1$ AND INCREASING; $a / w=(a / w)_{1}$

$t_{2}: \quad \dot{K}_{1}=0\left(K_{1} \max \right)$ FOR $a / w=(a / w)_{1} ;$ THE START OF WPS FOR $(a / w)_{1}$

$t_{3}: \quad \dot{K}_{1}=0\left(K_{1} \max \right)$ FOR $a / w=(a / w)_{2} ;$ THE START OF WPS 1

$t_{4}: \quad K_{1} / K_{1 c}=1$ AND INCREASING FOR $a / w=(a / w)_{2}$

$t_{5}: \quad \dot{K}_{1}=0\left(K_{1} \min \right)$ FOR $a / w=(a / w)_{2}$

$t_{6}: \quad \dot{K}_{1}=0\left(K_{1} \max \right)$ FOR $a / w=(a / w)_{2}:$ THE START OF WPS2

\section{CRITERIA:}

1. $t_{2}-t_{1} \geqslant 30 \mathrm{~s}$

2. $K_{1} / K_{1 c} \geqslant 1.25$ AT $t_{2}, a / w=(a / w)_{1}$

3. $K_{1} / K_{1 c} \geqslant 1.25$ AT $t_{5}, a / w=(a / w)_{2}$

4. $\quad K_{12}(\max ) / K_{11}(\max ) \geqslant 1.05, a / w=(a / w)_{2}$

5. $\dot{K}_{1}(a v) \leqslant-6.6 \mathrm{MPa} \cdot \sqrt{\mathrm{m}} / \mathrm{min}, \mathrm{a} / \mathrm{w}=(\mathrm{a} / \mathrm{w})_{2}, \mathrm{t}_{3}<\mathrm{t}<\mathrm{t}_{5}$

6. $T \leqslant T_{\text {CVN } 41}+50^{\circ} \mathrm{C}, a / w=(a / w)_{2}, t_{4}<t<t_{6}$

7. $T>T_{D}$ FOR LOCUS OF a/w SATISFYING $K_{1}=K_{1 a}, t_{5}<t<t_{6}$

8. $(a / w)_{U S A}<(a / w)_{L I G}, t_{6}<t_{U S I}$ 
ORNL-DWG 83-5461 ETD

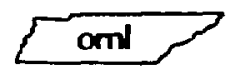

\section{CRITICAL CRACK DEPTH AND K, VS TIME FOR PTS TRANSIENT T2 OF TABLE 1}
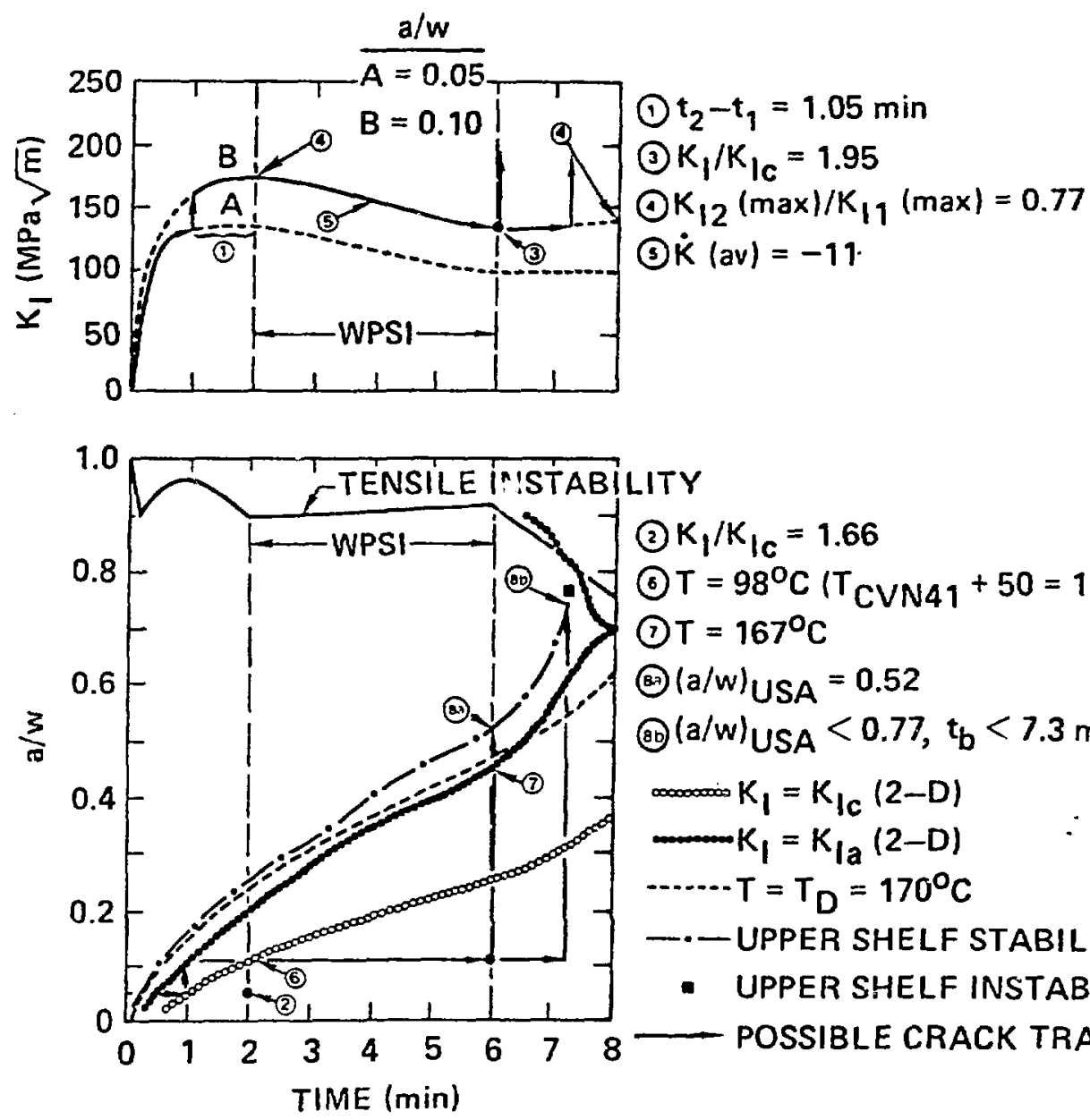

(2) $K_{1} / K_{1 C}=1.66$

(6) $\mathrm{T}=98^{\circ} \mathrm{C}\left(\mathrm{T}_{\mathrm{CVN} 41}+50=102\right)$

(ㄱ) $\mathrm{T}=167^{\circ} \mathrm{C}$

(ㄱ) $(a / w) \cup S A=0.52$

(으 $(a / w)_{U S A}<0.77, t_{b}<7.3 \mathrm{~min}$

$K_{1}=K_{l c}(2-D)$

$-K_{1}=K_{1 a}(2-D)$

-..... $T=T_{D}=170^{\circ} \mathrm{C}$

---UPPER SHELF STABILITY

- UPPER SHELF INSTABILITY POSSIBLE CRACK TRAJECTORY 